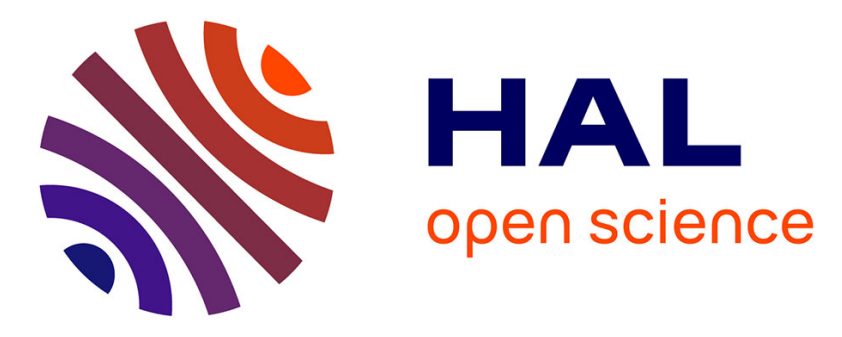

\title{
Evolution of cation and spin orders in the double-double-double perovskite series $\mathrm{Ca} \times \mathrm{Mn} 2-\mathrm{x}$ FeReO 6
}

Graham Mcnally, Angel Arévalo-López, Francois Guillou, Pascal Manuel, J. Paul Attfield

\section{To cite this version:}

Graham Mcnally, Angel Arévalo-López, Francois Guillou, Pascal Manuel, J. Paul Attfield. Evolution of cation and spin orders in the double-double-double perovskite series Ca x Mn $2-\mathrm{x}$ FeReO 6 . Physical Review Materials, 2020, 4 (6), 10.1103/PhysRevMaterials.4.064408 . hal-03088342

\section{HAL Id: hal-03088342 https://hal.science/hal-03088342}

Submitted on 5 Jan 2021

HAL is a multi-disciplinary open access archive for the deposit and dissemination of scientific research documents, whether they are published or not. The documents may come from teaching and research institutions in France or abroad, or from public or private research centers.
L'archive ouverte pluridisciplinaire HAL, est destinée au dépôt et à la diffusion de documents scientifiques de niveau recherche, publiés ou non, émanant des établissements d'enseignement et de recherche français ou étrangers, des laboratoires publics ou privés. 


\title{
Evolution of cation and spin orders in the double-double-double perovskite series $\mathrm{Ca}_{x} \mathrm{Mn}_{2-x} \mathrm{FeReO}_{6}$
}

\author{
Graham M. McNally, ${ }^{1,2}$ Angel M. Arévalo-López $\odot,{ }^{1,3}$ Francois Guillou, ${ }^{4}$ Pascal Manuel, ${ }^{5}$ and J. Paul Attfield $\odot^{1, *}$ \\ ${ }^{1}$ Centre for Science at Extreme Conditions (CSEC) and School of Chemistry, University of Edinburgh, \\ Peter Guthrie Tait Road, Edinburgh EH9 3FD, United Kingdom \\ ${ }^{2}$ Max-Plank-Institut für Festkörperforschung, Heisenbergstrasse 1, D-70569 Stuttgart, Germany \\ ${ }^{3}$ Université Lille, CNRS, Centrale Lille, Université Artois, UMR 8181, UCCS, Unité de Catalyse et Chimie du Solide, F-59000 Lille, France \\ ${ }^{4}$ ESRF, The European Synchrotron Radiation Facility, 71 Avenue des Martyrs CS40220, F-38043 Grenoble Cedex 09, France \\ ${ }^{5}$ STFC Rutherford Appleton Lab, ISIS Facility, Harwell Science and Innovation Campus, Didcot OX11 OQX, United Kingdom
}

(Received 7 April 2020; revised manuscript received 11 May 2020; accepted 15 May 2020;

published 9 June 2020)

\begin{abstract}
Variations of perovskite superstructure type and magnetic properties across the high-pressure $\mathrm{Ca}_{x} \mathrm{Mn}_{2-x} \mathrm{FeReO}_{6}$ series have been investigated by powder neutron-diffraction, $\mathrm{x}$-ray magnetic circular dichroism, and magnetization measurements. Monoclinic $P 2_{1} / n A_{2} B B^{\prime} \mathrm{O}_{6}$ double perovskite solid solutions with rocksalt-type ordering of $B / B^{\prime}$-Fe/Re cations but no $A$-cation order are discovered to exist only close to the end members $0<x<0.17$ and $1.73<x<2$. Compositions in the range $0.74<x<\sim 1.1$ adopt a tetragonal $\mathrm{P}_{2} / n A A^{\prime} B B^{\prime} \mathrm{O}_{6}$ double-double perovskite phase based on $\mathrm{CaMnFeReO}_{6}$, which has both columnar $A / A^{\prime}-\mathrm{Ca} / \mathrm{Mn}$ and rocksalt $B / B^{\prime}-\mathrm{Fe} / \mathrm{Re}$ cation orders. Two-phase coexistence of double and double-double perovskites occurs over wide regions between these limits. All samples are ferrimagnetic with Curie temperatures near $500 \mathrm{~K}$. Low-temperature Mn spin order is also observed in the Mn-rich double perovskites and the double-double perovskites. Spin reorientation transitions observed across all of the double perovskites are shown to result from $5 d^{2} \mathrm{Re}^{5+}$ orbital ordering, but this does not occur in the double-double perovskites. The Ca-rich double perovskites show significant magnetic coercivity at low temperatures.
\end{abstract}

DOI: 10.1103/PhysRevMaterials.4.064408

\section{INTRODUCTION}

$\mathrm{ABO}_{3}$ perovskite oxide materials have many outstanding physical properties and these can be further tuned through structural variations arising from cation order. Cation order of two different $A$ - or $B$-site cations in a $1: 1$ ratio leads to structural derivatives known as double perovskites [1]. These types of 1:1 order can occur with rocksalt, columnar, and layered arrangements. The most common form of double perovskites possesses a 1:1 rocksalt order of $B / B^{\prime}$ cations, with a general formula of $A_{2} B B^{\prime} \mathrm{O}_{6}$, often with a large charge difference between $B$ and $B^{\prime}$ that promotes cation order through minimizing electrostatic repulsion [2]. Less commonly, some perovskites display long-range orders of different cations of both the $A$ - and the $B$-site cations [1] and these $A A^{\prime} B B^{\prime} \mathrm{O}_{6}$ materials are described here as "double-double perovskites," for example, $\mathrm{CaMnFeReO}_{6}$ as shown in Fig. 1 and described further below.

$A_{2} B B^{\prime} \mathrm{O}_{6}$ double perovskites with a $1: 1$ rocksalt order of $B / B^{\prime}$ cations may exhibit ferrimagnetic and half metallic behaviors in cases where large spin $3 d B$ cations and small spin $4 d$ or $5 d B^{\prime}$ cations are well ordered, as in the well-known example of $\mathrm{Sr}_{2} \mathrm{FeMoO}_{6}[3,4]$, and related materials [5] such as $\mathrm{Ca}_{2} \mathrm{FeReO}_{6}$ [6]. However, the latter is more complex [7-11] as it undergoes a phase transition from a ferrimagnetic metallic to a ferrimagnetic insulating phase below $140 \mathrm{~K}$, which has

\footnotetext{
*j.p.attfield@ed.ac.uk
}

been identified as the orbital ordering transition for the $5 d^{2}$ state of $\mathrm{Re}^{5+}$ [12], and other phenomena such as electronic phase separation based on different spin-orbit coupled orders are also reported $[13,14]$. These $A_{2} B B^{\prime} \mathrm{O}_{6}$ double perovskites stabilized by nonmagnetic $A$-site cations such as $A=\mathrm{Ca}, \mathrm{Sr}$, and $\mathrm{Ba}$ are typically prepared at ambient pressure, but it has recently been shown that analogs with the magnetic transition metal cation $\mathrm{Mn}^{2+}\left(3 d^{5}\right.$, spin $\left.S=5 / 2\right)$ at the $A$ site can be prepared at high temperatures, for example, $\mathrm{Mn}_{2} B \mathrm{SbO}_{6}$ ( $B=\mathrm{Sc}$ [15], $\mathrm{Cr}$ [16], and $\mathrm{Fe}$ [17] $), \mathrm{Mn}_{2} B \mathrm{ReO}_{6}(B=\mathrm{Mn}$ $[18,19]$, Fe [20,21], and Co [22]), $\mathrm{Mn}_{2}\left(\mathrm{Fe}_{0.8} \mathrm{Mo}_{0.2}\right) \mathrm{MoO}_{6}$ [23], and $\mathrm{Mn}_{2} \mathrm{MnTeO}_{6}$ [24]. $\mathrm{Mn}_{2} \mathrm{FeReO}_{6}$ is notable as having a ferrimagnetic insulating ground state similar to that of $\mathrm{Ca}_{2} \mathrm{FeReO}_{6}$, a high Curie temperature of $T_{\mathrm{C}}=520 \mathrm{~K}$, a large magnetization of $5.0 \mu_{\mathrm{B}}$ f.u. $^{-1}$ at $75 \mathrm{~K}$ (f.u. $=$ formula unit), and low-temperature switching of the sign of magnetoresistance attributed to magnetic frustration between $A$-site $\mathrm{Mn}$ and $B / B^{\prime}$-site $\mathrm{Fe} / \mathrm{Re}$ spins. When half of the $\mathrm{Mn}^{2+}$ was replaced by $\mathrm{Ca}^{2+}$, the product $\mathrm{CaMnFeReO}_{6}$ was found to have an $A A^{\prime} B B^{\prime} \mathrm{O}_{6}$ double-double perovskite structure with columnar 1:1 $\mathrm{A} / \mathrm{A}^{\prime}$-site order of ten-coordinate $\mathrm{Ca}^{2+}$ and four-coordinate $\mathrm{Mn}^{2+}$ as well as rocksalt $1: 1 \mathrm{~B} / \mathrm{B}^{\prime}-\mathrm{Fe} / \mathrm{Re}$ cation order [25]. This tetragonal $P 4_{2} / n$ double-double perovskite structure type is also observed in the $R \mathrm{MnMnSbO}_{6}(R=\mathrm{La}, \mathrm{Pr}, \mathrm{Nd}, \mathrm{Sm}$ $[26,27])$ series as well as in $\mathrm{CaMn} M \mathrm{ReO}_{6}(M=\mathrm{Mn}[25]$, $\mathrm{Co}$, and $\mathrm{Ni}$ [28]) and $\mathrm{Ca}\left(\mathrm{Mn}_{0.5} \mathrm{Cu}_{0.5}\right) \mathrm{FeReO}_{6}$ [25]. These double-double perovskites all require high-pressure synthesis.

$\mathrm{Mn}_{2} \mathrm{FeReO}_{6}$ and $\mathrm{Ca}_{2} \mathrm{FeReO}_{6}$ both have monoclinic $P 2_{1} / n$ double perovskite structures, so the above observation that 


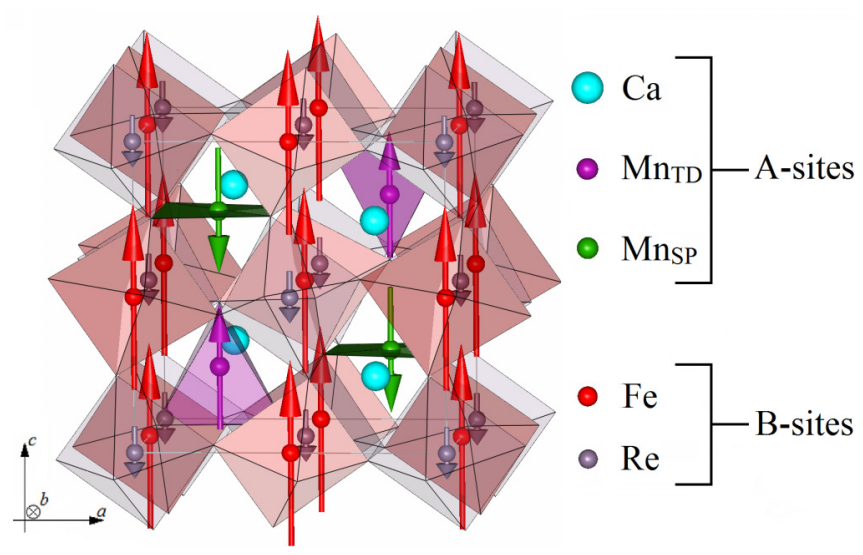

FIG. 1. Crystal and magnetic structures of the tetragonal $P 4_{2} / n A A^{\prime} B B^{\prime} \mathrm{O}_{6}$ double-double perovskite $\mathrm{CaMnFeReO}_{6}$ showing columnar $A / A^{\prime}-\mathrm{Ca} / \mathrm{Mn}$ and rocksalt $B / B^{\prime}-\mathrm{Fe} / \mathrm{Re}$ cation orders. The $\mathrm{Mn}^{2+}$ cations occupy alternating tetrahedral $\left(\mathrm{Mn}_{\mathrm{TD}}\right)$ and square planar $\left(\mathrm{Mn}_{\mathrm{SP}}\right)$ sites within their column. There are thus five different cation sites in total in this structure type. Ferrimagnetic orders of $\mathrm{Fe} / \mathrm{Re}$ and of $\mathrm{Mn}_{\mathrm{TD}} / \mathrm{Mn}_{\mathrm{SP}}$ spins are observed at low temperatures.

their apparent $x=1$ solid solution $\mathrm{Ca}_{x} \mathrm{Mn}_{2-x} \mathrm{FeReO}_{6}$ in fact has a higher symmetry tetragonal $P 4_{2} / n$ double-double perovskite structure is unusual and has motivated the present study. Similar structural changes were not reported in other mixed-cation double perovskite systems [5]. Here, two further samples with nominal compositions $x=0.5$ and 1.5 have been prepared at high pressures to discover how structural properties and cation orders evolve between the double perovskites at $x=0$ and 2 and the double-double type at $x=1$. Investigations of magnetic properties and crystal and magnetic structures for the previously reported $x=0$ and 1 and the new $x=0.5$ and 1.5 samples are used to explore how phase formation and structure type, high-temperature ferrimagnetic order of $\mathrm{Fe} / \mathrm{Re}$ spins, and low-temperature $\mathrm{Mn}^{2+}$ spin ordering, $\mathrm{Re}^{5+}$ orbital ordering, and spin-reorientation transitions previously reported in the $x=0$ and 2 end members, vary with doping. Results for samples with nominal $x=0,0.5,1.0$, and 1.5 compositions will be presented, followed by a discussion of the structural and magnetic properties across the proposed $\mathrm{Ca}_{x} \mathrm{Mn}_{2-x} \mathrm{FeReO}_{6}$ phase diagram.

\section{EXPERIMENT}

Polycrystalline $\mathrm{Ca}_{x} \mathrm{Mn}_{2-x} \mathrm{FeReO}_{6}$ samples were prepared by high-pressure synthesis at $10 \mathrm{GPa}$ and $1673 \mathrm{~K}$ in a Walkertype multianvil module. The starting materials which were mixed in stoichiometric proportions were: $x=0-\mathrm{Mn}_{3} \mathrm{O}_{4}$, $\mathrm{Fe}_{3} \mathrm{O}_{4}$, and $\mathrm{ReO}_{2} ; x=0.5-\mathrm{CaMnO}_{3}, \mathrm{Mn}_{3} \mathrm{O}_{4}, \mathrm{Fe}_{3} \mathrm{O}_{4}$, and $\mathrm{ReO}_{2} ; x=1-\mathrm{CaMnO}_{3}, \mathrm{Ca}_{2} \mathrm{Fe}_{2} \mathrm{O}_{5}, \mathrm{Mn}_{3} \mathrm{O}_{4}, \mathrm{Fe}_{3} \mathrm{O}_{4}$, and $\mathrm{ReO}_{2}$; and $x=1.5-\mathrm{CaMnO}_{3}, \mathrm{Ca}_{2} \mathrm{Fe}_{2} \mathrm{O}_{5}$, and $\mathrm{ReO}_{2}$.

Powder neutron diffraction (PND) was performed on $\sim 60 \mathrm{mg}$ of each of these samples using the WISH diffractometer at the ISIS Neutron Facility [29], at temperatures from 2 to $300 \mathrm{~K}$. Powder synchrotron x-ray diffraction (PSXRD) data were collected for $\mathrm{CaMnFeReO}_{6}$ at the BL04-MSPD beamline at the ALBA facility (wavelength $\lambda=0.44214 \AA$ ). Room-temperature PSXRD was also performed on the $x=$
0.5 and 1.5 samples on beamline ID22 at the $\operatorname{ESRF}(\lambda=$ $0.39987 \AA$ ). The FULLPROF suite was used to analyze the powder-diffraction data [30]. The neutron-scattering lengths for $\mathrm{Ca}, \mathrm{Mn}, \mathrm{Fe}$, and $\mathrm{Re}$ of $4.70,-3.73,9.45$, and $9.2 \mathrm{fm}$, respectively, gave high contrast between the lighter metals $\mathrm{Ca}, \mathrm{Mn}$, and $\mathrm{Fe}$ in PND site occupancy refinements from which $\mathrm{Ca} / \mathrm{Mn}$ ratios in the components of multiphase samples were determined. X-ray refinements were used to quantify any $B / B^{\prime}$-Fe/Re antisite disorder.

X-ray absorption near-edge spectra (XANES) used to derive $\mathrm{X}$-ray magnetic circular dichroism $(\mathrm{XMCD})$ data were collected at the $\operatorname{Re} L_{2}, \operatorname{Re} L_{3}$, and Mn $K$ edges on beamline ID12 at the ESRF, at temperatures from 2 to $300 \mathrm{~K}$ and in applied field strengths up to $17 \mathrm{~T}$. The fluorescence of the samples was measured in backscattering geometry and the $\mathrm{x}$-ray-absorption spectra were corrected for self-absorption effects.

The zero-field-cooled and field-cooled thermal dependence of magnetization (under an applied field of $0.5 \mathrm{~T}$ ) was measured for all materials between 5 and $650 \mathrm{~K}$ and magnetic hysteresis loops were recorded in fields up to $7 \mathrm{~T}$.

\section{RESULTS}

\section{A. Powder diffraction \\ 1. $\mathrm{Mn}_{2} \mathrm{FeReO}_{6}(x=0)$}

$\mathrm{Mn}_{2} \mathrm{FeReO}_{6}$ is notable as an example of a double perovskite with all cation sites occupied by magnetic transition metal ions [20,21]; $A$-site $\mathrm{Mn}^{2+}\left(3 d^{5}, S=5 / 2\right)$ and $B$-site $\mathrm{Fe}^{3+}\left(3 d^{5}, S=5 / 2\right)$ and $\mathrm{Re}^{5+}\left(5 d^{2}, S=1\right)$. Ferrimagnetic $\mathrm{Fe}$ and Re spin ordering occurs at $T_{\mathrm{C}}=520 \mathrm{~K}$ and an additional antiferromagnetic order of $A$-site $\mathrm{Mn}^{2+}$ spins was observed below $T_{\mathrm{Mn}}=150 \mathrm{~K}$ leading to a spin reorientation transition of all sublattices due to frustration at $T_{\mathrm{sr}}=75 \mathrm{~K}$. The material reaches a maximum magnetization of $5.0 \mu_{\mathrm{B}}$ f.u. ${ }^{-1}$ (the largest reported value for transition metal based double perovskites) at $75 \mathrm{~K}$ and falls on further cooling. The sign of magnetoresistance switches from negative above the canting transition (MR $=-19 \%$ at $7 \mathrm{~T}, 100 \mathrm{~K}$ ) to positive below (MR $=+265 \%$ at $7 \mathrm{~T}, 20 \mathrm{~K})$.

New high-resolution PND data obtained on this material using the WISH diffractometer have enabled a more thorough refinement of the magnetic structures and associated structural distortions to be carried out. The structural symmetry is monoclinic $P 2_{1} / n$ throughout and the spin structures have propagation vector $\boldsymbol{k}=\left(\begin{array}{lll}0 & 0 & 0\end{array}\right)$ with irreducible representations as shown previously [21]. No $A / B$ antisite disorder was found in initial fits to PND data, and all sites were fixed at full occupancy. Room-temperature lattice parameters and magnetic transition temperatures for $\mathrm{Mn}_{2} \mathrm{FeReO}_{6}$ and other $\mathrm{Ca}_{x} \mathrm{Mn}_{2-x} \mathrm{FeReO}_{6}$ samples are shown in Table I. Full tables of refined structural and magnetic parameters for $\mathrm{Mn}_{2} \mathrm{FeReO}_{6}$ are shown in [31] and results are summarized in Figs. 2 and 3. Magnetic diffraction from only ferrimagnetic order of $\mathrm{Fe} / \mathrm{Re}$ spins is present at $200-300 \mathrm{~K}$. This was previously fitted with moments parallel to the $c$ axis [21], but the present study showed that these spins lie in the $a c$ plane with both components active, e.g., $m_{x}=1.7(2)$ and $m_{z}=3.68(8) \mu_{\mathrm{B}}$ at $200 \mathrm{~K}$ [31]. Re moments are too small to be refined indepen- 
TABLE I. Room-temperature lattice parameters and magnetic ordering transition temperatures ( $T_{\mathrm{C}}$ : Curie; $T_{\mathrm{Mn}}: A$-site Mn spin order; $T_{\text {sr }}$ : spin reorientation and Re-orbital order) for $\mathrm{Ca}_{x} \mathrm{Mn}_{2-x} \mathrm{FeReO}_{6}$ samples. Double and double-double perovskite phases respectively have monoclinic space group (SG) $P 2_{1} / n$ and tetragonal $P 4_{2} / n$. Curie temperatures are determined from magnetization data, with only a single value measured for the two-phase $x=0.5$ and 1.5 samples. All other values are from PND, except for the $x=1.5 P 4_{2} / n$ phase which was only analyzed from PSXRD data,

\begin{tabular}{|c|c|c|c|c|c|c|c|}
\hline \multirow{2}{*}{$\begin{array}{l}\text { Nominal } x \\
\text { SG }\end{array}$} & \multirow{2}{*}{$\begin{array}{c}0 \\
P 2_{1} / n\end{array}$} & \multicolumn{2}{|c|}{0.5} & \multirow{2}{*}{$\begin{array}{c}1 \\
P 4_{2} / n\end{array}$} & \multicolumn{2}{|c|}{1.5} & \multirow{2}{*}{$\begin{array}{c}2 \\
P 2_{1} / n\end{array}$} \\
\hline & & $P 2_{1} / n$ & $P 4_{2} / n$ & & $P 4_{2} / n$ & $P 2_{1} / n$ & \\
\hline$x$ & 0 & $0.17(3)$ & $0.74(2)$ & 1 & 1 & $1.73(8)$ & 2 \\
\hline$a / \AA$ & $5.2087(4)$ & $5.2339(7)$ & $7.612(1)$ & $7.6311(5)$ & $7.66839(6)$ & $5.3843(7)$ & $5.39023(6)$ \\
\hline$b / \AA$ & $5.3687(5)$ & $5.3929(7)$ & & & & $5.5168(7)$ & $5.51648(6)$ \\
\hline$c / \AA$ & $7.5998(6)$ & $7.610(1)$ & $7.603(1)$ & $7.6266(7)$ & $7.64776(7)$ & 7.683(1) & $7.67191(8)$ \\
\hline$\beta /$ degrees & $90.06(2)$ & $89.95(2)$ & & & & $89.996(5)$ & $90.2212(6)$ \\
\hline$T_{\mathrm{C}} / \mathrm{K}$ & 520 & \multicolumn{2}{|c|}{500} & 500 & \multicolumn{2}{|c|}{490} & 540 \\
\hline$T_{\mathrm{Mn}} / \mathrm{K}$ & 175 & 130 & 75 & 70 & & & \\
\hline$T_{\mathrm{sr}} / \mathrm{K}$ & 75 & 100 & & & & 100 & 140 \\
\hline Reference & this study & \multicolumn{2}{|c|}{ this study } & [25] & \multicolumn{2}{|c|}{ this study } & [12] \\
\hline
\end{tabular}

dently and so Re spin components were constrained to have $-20 \%$ of $\mathrm{Fe}$ spin values, as used previously [21]. Induced antiferromagnetic order of $A$-site $\mathrm{Mn}$ spins is observed to emerge between 175 and $200 \mathrm{~K}$, and refinements give three Cartesian spin components of comparable magnitude, e.g., $m_{x}=1.20(7), m_{y}=0.98(8)$, and $m_{z}=1.35(6) \mu_{\mathrm{B}}$ at $80 \mathrm{~K}$. Both $\mathrm{Fe} / \mathrm{Re}$ and $\mathrm{Mn}$ spins were fitted with three Cartesian spin components below the $75 \mathrm{~K}$ canting transition. Magnetostructural coupling is apparent as anomalies in the thermal evolution of lattice parameters and some $\mathrm{Fe}-\mathrm{O}$ and $\mathrm{Re}-\mathrm{O}$ bonds are observed at the spin canting transition at $75 \mathrm{~K}$ (Fig. 2). The expansion of one of the pairs of $\mathrm{Re}-\mathrm{O}$ bond distances below $T_{\text {sr }}=75 \mathrm{~K}$ is similar to that reported for the $\mathrm{Re}^{5+}$ orbital ordering transition in $\mathrm{Ca}_{2} \mathrm{FeReO}_{6}$ at $140 \mathrm{~K}$ which also drives a spin reorientation [12]. This suggests that a coupled $\mathrm{Re}^{5+}$ orbital ordering and spin reorientation transition occurs in both $\mathrm{Mn}_{2} \mathrm{FeReO}_{6}$ and $\mathrm{Ca}_{2} \mathrm{FeReO}_{6}$ at low temperatures (and this is supported by observations on intermediate double perovskite phases in the following sections).

The ordered spin structures at representative temperatures are shown in Fig. 3(a). Thermal variations of spin components and tilt angles in Fig. 3(b) show that the ferrimagnetic Fe/Re spins are tilted by $\sim 25^{\circ}$ from the $c$ direction in the $a c$ plane at high temperatures, which corresponds to the $\theta_{\text {Tilt }}$ tilting angle of the $\mathrm{FeO}_{6}$ octahedra so this likely defines the easy axis. Antiferromagnetic Mn order emerges below $200 \mathrm{~K}$ and the canting transition at $75 \mathrm{~K}$ tilts $\mathrm{Fe} / \mathrm{Re}$ moments further to $50^{\circ}$ from $c$, and adds a small antiferromagnetic component of $0.5 \mu_{\mathrm{B}}$ for Fe parallel to the $b$ axis. The introduced tilting angle for the Fe moment in the $a b$ plane $\phi_{\mathrm{Fe}} \approx 12^{\circ}$ is close to the corresponding octahedral tilt angle $\phi_{\text {Tilt }}$, showing that local structure again determines the easy axis. The Fe moments are essentially fully ordered, with a magnitude of $4.9 \mu_{\mathrm{B}}$ at $1.5 \mathrm{~K}$, and are canted by $24^{\circ}$ from the directions of their neighbors in successive $a c$ layers, which gives rise to the positive magnetoresistance effect described previously [21].

\section{2. $\mathrm{Ca}_{0.5} \mathrm{Mn}_{1.5} \mathrm{FeReO}_{6}(x=0.5)$}

This composition has the ideal cation ratio to form a 1:3 $A$-site and 1:1 $B$-site ordered perovskite, as observed in
$\mathrm{CaCu}_{3} \mathrm{Fe}_{2} \mathrm{Re}_{2} \mathrm{O}_{12}$ [32]. However, this ordering type was not observed and samples prepared with the nominal $x=0.5$ composition were found to consist of two phases. One is a double perovskite with monoclinic $P 2_{1} / n$ symmetry, like $\mathrm{Mn}_{2} \mathrm{FeReO}_{6}$ above, and the other is a double-double perovskite with tetragonal $P 4_{2} / n$ symmetry having $1: 1$ orders of $A$ and $B$ site cations as found in $\mathrm{CaMnFeReO}_{6}$ [25]. These phases are labeled as $x=0.5(M)$ and $x=0.5(T)$ respectively. The structures of both materials were fitted to PSXRD and PND data as shown in Fig. 4. Full tables of refined structural and magnetic parameters are shown in [31]. The two phases are found to coexist in approximately equal proportions, with refined weight fractions of $49(3) \%$ of $0.5(M)$ and $51 \%$ of $0.5(T)$ from PND fits.

To explore whether the chemical compositions of the $x=0.5(M)$ and $x=0.5(T)$ phases differ from the nominal value, $A$-site $\mathrm{Ca} / \mathrm{Mn}$ ratios were refined in fits to the PND data. The $x=0.5(M)$ phase has a nominal $\left(\mathrm{Ca}_{0.5} \mathrm{Mn}_{1.5}\right) \mathrm{FeReO}_{6}$ double perovskite formulation, but the refined composition was $\left(\mathrm{Ca}_{0.17(3)} \mathrm{Mn}_{1.83}\right) \mathrm{FeReO}_{6}$ showing that it is $\mathrm{Ca}$ poor relative to the average composition. The $x=0.5(T)$ phase would have nominal composition $\left(\mathrm{Ca}_{0.5} \mathrm{Mn}_{0.5}\right) \mathrm{MnFeReO}_{6}$ as a double-double perovskite, but refinement gave $\left(\mathrm{Ca}_{0.74(2)} \mathrm{Mn}_{0.26}\right) \mathrm{MnFeReO}_{6}$ demonstrating that it is Ca rich. The observation that the $x=0.5(M)$ and $x=$ $0.5(T)$ phases have respective refined $x$ values of $0.17(3)$ and $0.74(2)$ clearly demonstrates that a chemical phase separation (miscibility gap) exists in this region of the $\mathrm{Ca}_{x} \mathrm{Mn}_{2-x} \mathrm{FeReO}_{6}$ system under the given synthesis conditions. A Ca-poor double perovskite phase exists over the approximate range $0<x<0.17$, a double-double perovskite is found for $x>$ 0.74 , and two-phase coexistence occurs between these limits. Similar amounts of $B / B^{\prime}-\mathrm{Fe} / \mathrm{Re}$ antisite disorder were found in the two structures from PSXRD refinements $[5.8(1) \%$ for $x=0.5(M)$ and $5.0(1) \%$ for $x=0.5(T)$ ] demonstrating that the $B / B^{\prime}$ site ordering is unaffected by the phase separation and differences between the double and double-double perovskite structures.

The $x=0.5(M)$ phase is crystallographically and magnetically similar to the $x=0$ material and the same magnetic structures are observed as a function of temperature as shown 
(a)

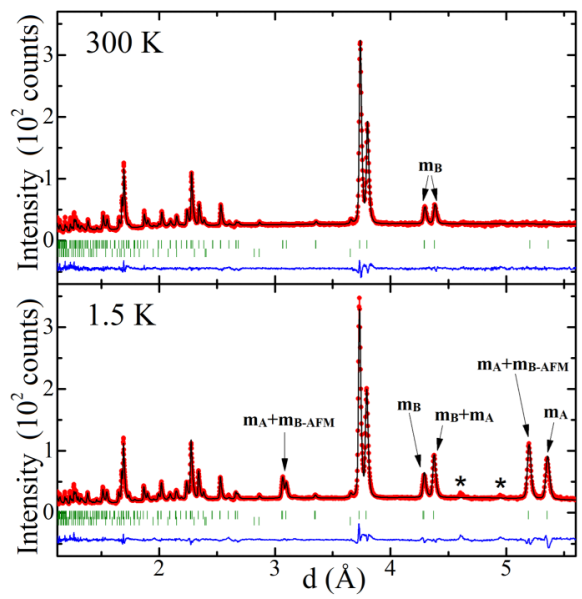

(c)

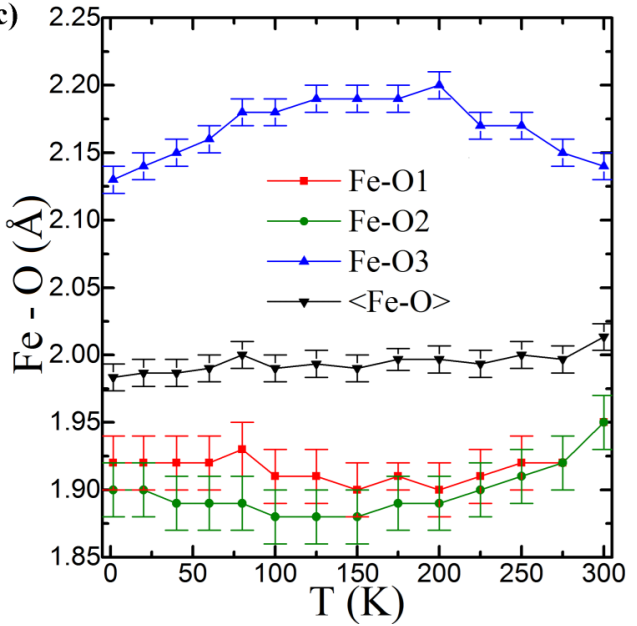

(b)

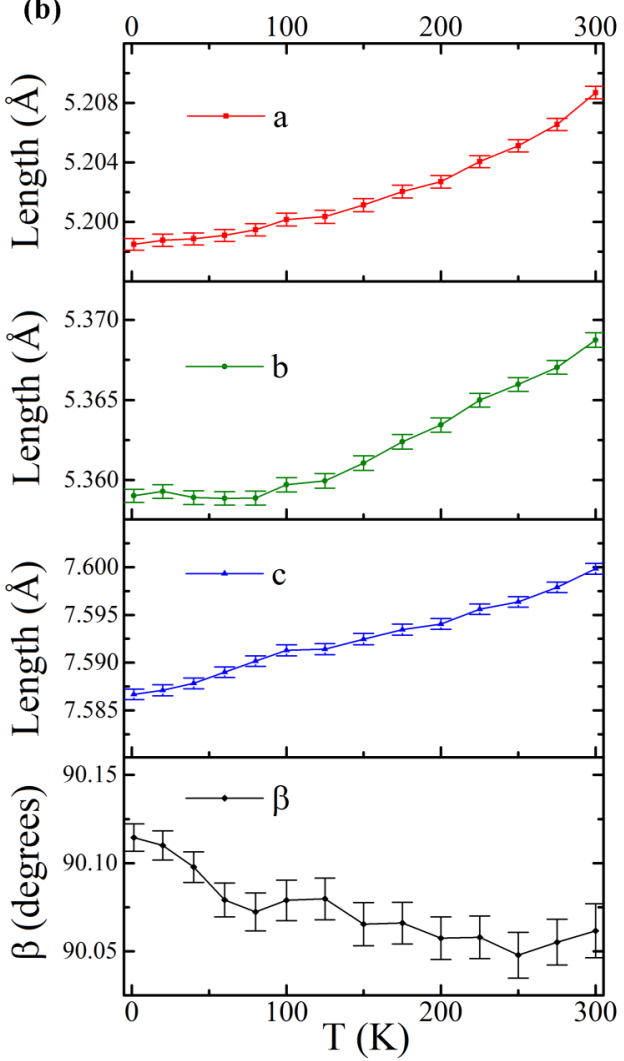

(d)

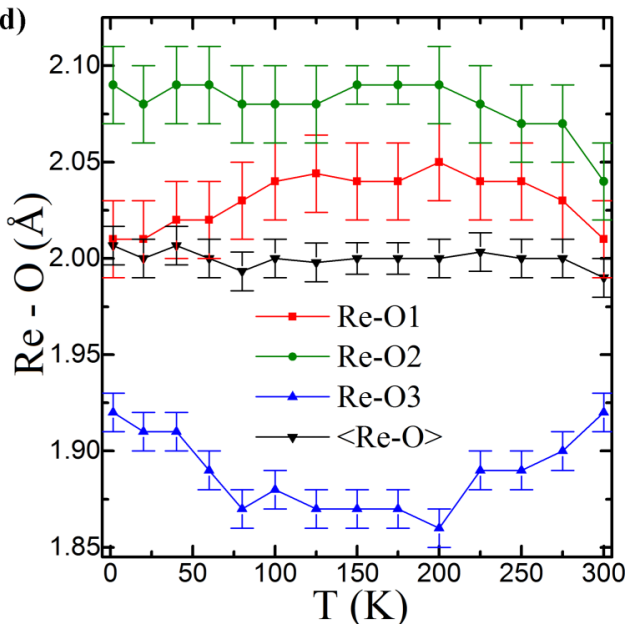

FIG. 2. Powder neutron-diffraction results for $\mathrm{Mn}_{2} \mathrm{FeReO}_{6}$. (a) Profile fits at 1.5 and $300 \mathrm{~K}$. Labels $m_{\mathrm{A}}$ and $m_{\mathrm{B}}$ refer to magnetic reflections with contributions from $A(\mathrm{Mn})$ and $B(\mathrm{Fe} / \mathrm{Re})$ site spin order, respectively. Lower markers show the fit of a trace of $\mathrm{ReO}_{2}$ impurity, and asterisks mark peaks from a trace of $\mathrm{MnFe}_{3} \mathrm{O}_{5}$. Plots show temperature variations of refined quantities for $\mathrm{Mn}_{2} \mathrm{FeReO}_{6}$; (b) monoclinic lattice parameters, (c) Fe-O bond lengths, and (d) Re-O bond lengths.

by the evolution of magnetic peak intensities [31]. The onset of Mn spin order is between 100 and $200 \mathrm{~K}$ (estimated $T_{\mathrm{Mn}} \approx$ $130 \mathrm{~K}$ ), and the spin reorientation and $\mathrm{Re}^{5+}$ orbital ordering transition occurs at $T_{\mathrm{sr}} \approx 100 \mathrm{~K}$. It is notable that this a higher temperature than in the undoped $x=0$ sample despite the introduced $A$-site cation disorder, and in keeping with the above suggestion that this is the same transition varying between $75 \mathrm{~K}$ in $\mathrm{Mn}_{2} \mathrm{FeReO}_{6}$ and $140 \mathrm{~K}$ in $\mathrm{Ca}_{2} \mathrm{FeReO}_{6}$. Thermal variations of spin components and tilt angles in [31] show a similar switch in the Fe moment easy axis at $T_{\text {sr }}$ as for undoped $\mathrm{Mn}_{2} \mathrm{FeReO}_{6}$.
The crystal and magnetic structures of the double-double perovskite $x=0.5(T)$ phase are found to be qualitatively the same as for the $x=1$ material, with high-temperature ferrimagnetic order of the Fe and $\operatorname{Re}$ spins $\left(T_{\mathrm{C}}=500 \mathrm{~K}\right)$, and a second ferrimagnetic transition near $T_{\mathrm{Mn}}=50 \mathrm{~K}$ where $\mathrm{Mn}$ spins at the two distinct four-coordinated sites in the $A$-site columns order antiparallel to each other as shown in Fig. 1. All ordered spins are parallel to the $c$ axis. No ordering of the Mn spins on Ca sites was observed.

Temperature variations of lattice parameters in Figs. 4(c) and 4(d) reveal magnetostructural anomalies at the 
(a)

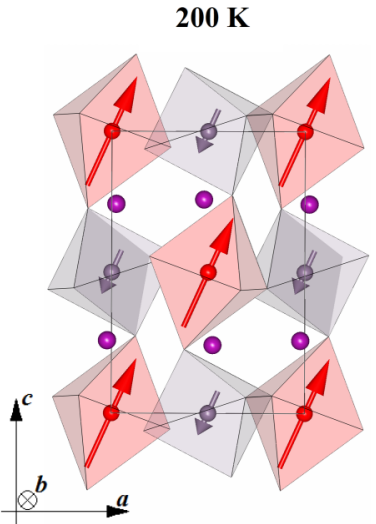

(b)

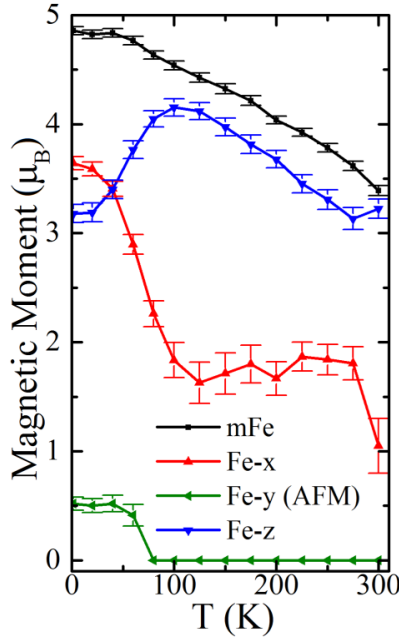

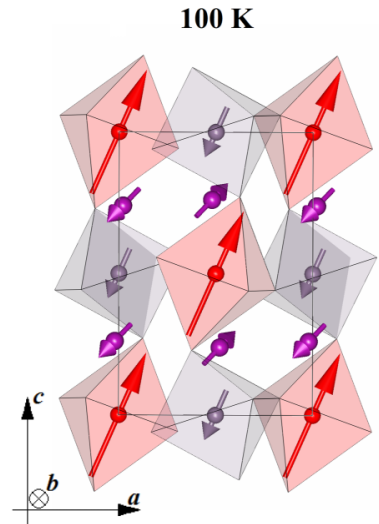

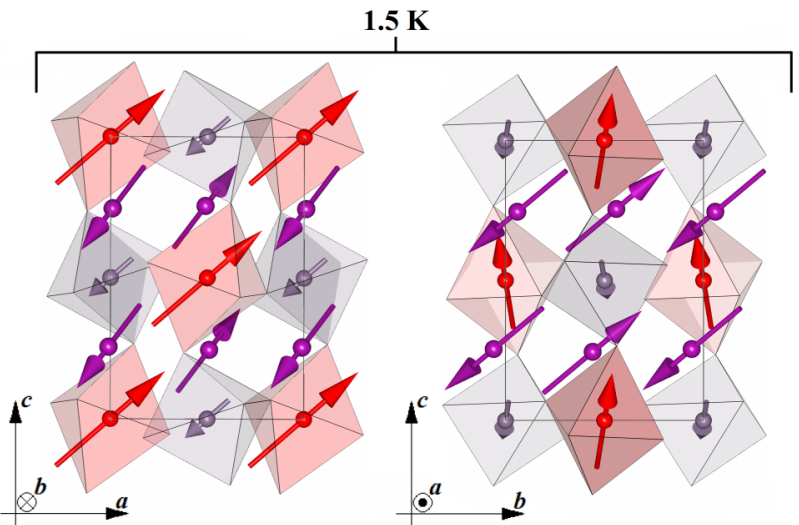

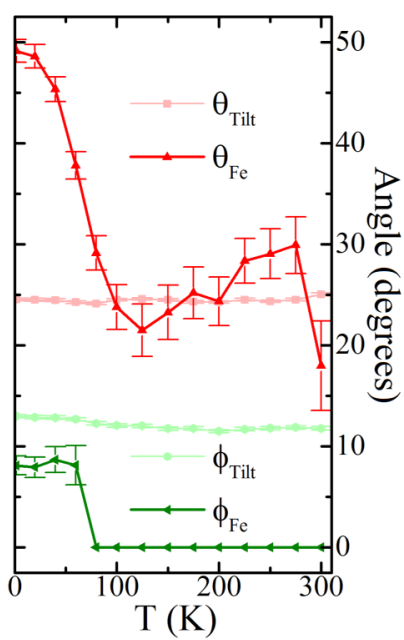

(c)
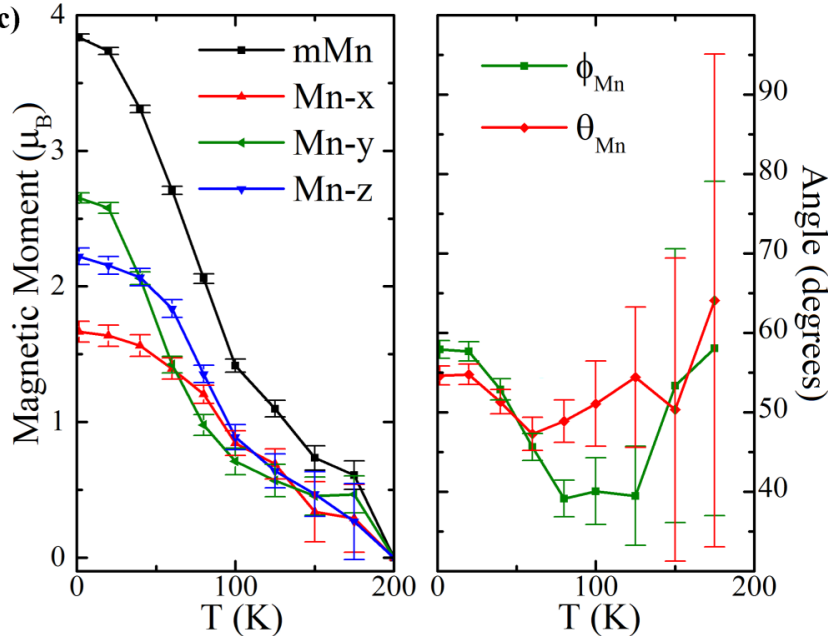

FIG. 3. (a) Refined magnetic structures of $\mathrm{Mn}_{2} \mathrm{FeReO}_{6}$ at 200, 100, and $1.5 \mathrm{~K}$. Fe atoms are shown in red, Re in grey, and Mn in purple. The 1.5-K magnetic structure is shown in the $a c$ plane, as well as the $b c$ plane to emphasize the $b$-axis antiferromagnetic Fe/Re component to the spin order. Plots show (left) the total magnetic moment and cartesian components of spin order, and (right) tilt angles for (b) Fe and (c) Mn spins. $\theta_{\mathrm{Fe}(\mathrm{Mn})}$ is the angle between the $c$ axis and the $\mathrm{Fe}(\mathrm{Mn})$ spin direction in the $a c$ plane. $\phi_{\mathrm{Fe}(\mathrm{Mn})}$ is the angle between the $a$ axis and the $\mathrm{Fe}(\mathrm{Mn})$ spin direction in the $a b$ plane. Angles $\theta_{\text {Tilt }}$ and $\phi_{\text {Tilt }}$ in (b) show the tilts of the $\mathrm{FeO}_{6}$ octahedra defined correspondingly.

$T_{\mathrm{sr}}=100 \mathrm{~K}$ spin reorientation transition for the $x=0.5(M)$ phase, and at $T_{\mathrm{Mn}}=50 \mathrm{~K}$ for $x=0.5(T)$. The sharp increase in $c$ below the $50-\mathrm{K} \mathrm{Mn}$ spin ordering for the $x=0.5(T)$ double-double perovskite phase leads to zero or negative thermal expansion between 25 and $50 \mathrm{~K}$ with calculated expansion coefficient $\alpha_{V}=(1 / V)(\Delta V / \Delta T)=$ $-10( \pm 10) \times 10^{-6} \mathrm{~K}^{-1}$.

\section{3. $\mathrm{CaMnFeReO}_{6}(x=1)$}

As previously reported this sample adopts a single phase, double-double perovskite structure in the tetragonal $P 4_{2} / n$ space group with both $A$ - and $B$-site crystallographic order, $A$-site $\mathrm{Ca} / \mathrm{Mn}$ order being of the columnar type and $B$-site $\mathrm{Fe} / \mathrm{Re}$ order in a rocksalt pattern [25]. Fe and Re spins order ferrimagnetically at $T_{\mathrm{C}}=500 \mathrm{~K}$, and $\mathrm{Mn}$ spins order at a second ferrimagnetic transition at $70 \mathrm{~K}$. The magnetic structure is collinear with all magnetic moments oriented along the $c$ axis, as shown in Fig. 1, and no magnetic reorientation transition was observed down to $2 \mathrm{~K}$.

\section{4. $\mathrm{Ca}_{1.5} \mathrm{Mn}_{0.5} \mathrm{FeReO}_{6}(x=1.5)$}

Two-phase behavior is observed in PSXRD data with a majority [88.0(2) wt. \%] monoclinic $P 2_{1} / n$ double perovskite $x=1.5(M)$ phase and a minority double-double perovskite $x=1.5(T)$ phase with tetragonal $P 4_{2} / n$ symmetry present. The latter was fitted to PSXRD data using the model for $x=1 \mathrm{CaMnFeReO}_{6}$ without varying site occupancies as attempts to refine the $\mathrm{Ca} / \mathrm{Mn}$ ratio did not give statistically significant occupancy of $\mathrm{Mn}$ sites by $\mathrm{Ca}$. Hence we estimate that the upper Ca limit for the $x=1.5(T)$ double-double perovskite phase is no more than $x \sim 1$. 1 . The contribution from the $x=1.5(T)$ phase was too small to be refined in fits to the PND data, and only the majority $x=1.5(M)$ crystal and magnetic structures were fitted. Results are shown in Fig. 5 and in [31]. The composition of the $x=1.5(M)$ phase is found to be $\left(\mathrm{Ca}_{1.73(8)} \mathrm{Mn}_{0.27}\right) \mathrm{FeReO}_{6}$, from site occupancy refinement during the PND fitting, so this likely represents the upper limit of $\mathrm{Mn}$ substitution for $\mathrm{Ca}$ in the $\mathrm{Ca}_{2} \mathrm{FeReO}_{6}$ structure. The discovery that the $x=1.5(T)$ and $x=1.5(M)$ phases have respective refined $x$ values of $\sim 1.1$ and 1.73(8) shows that a second miscibility gap exists in this Ca-rich 
(a)

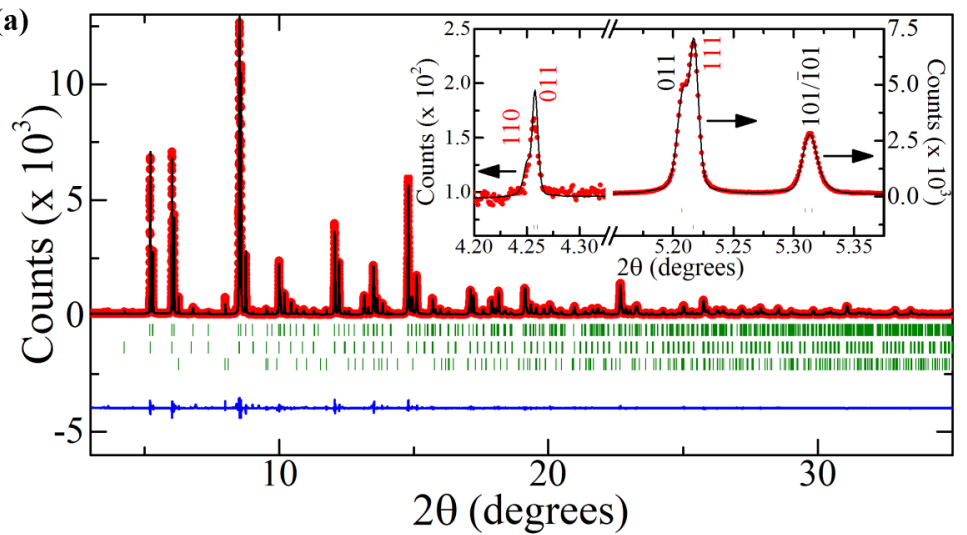

(b)

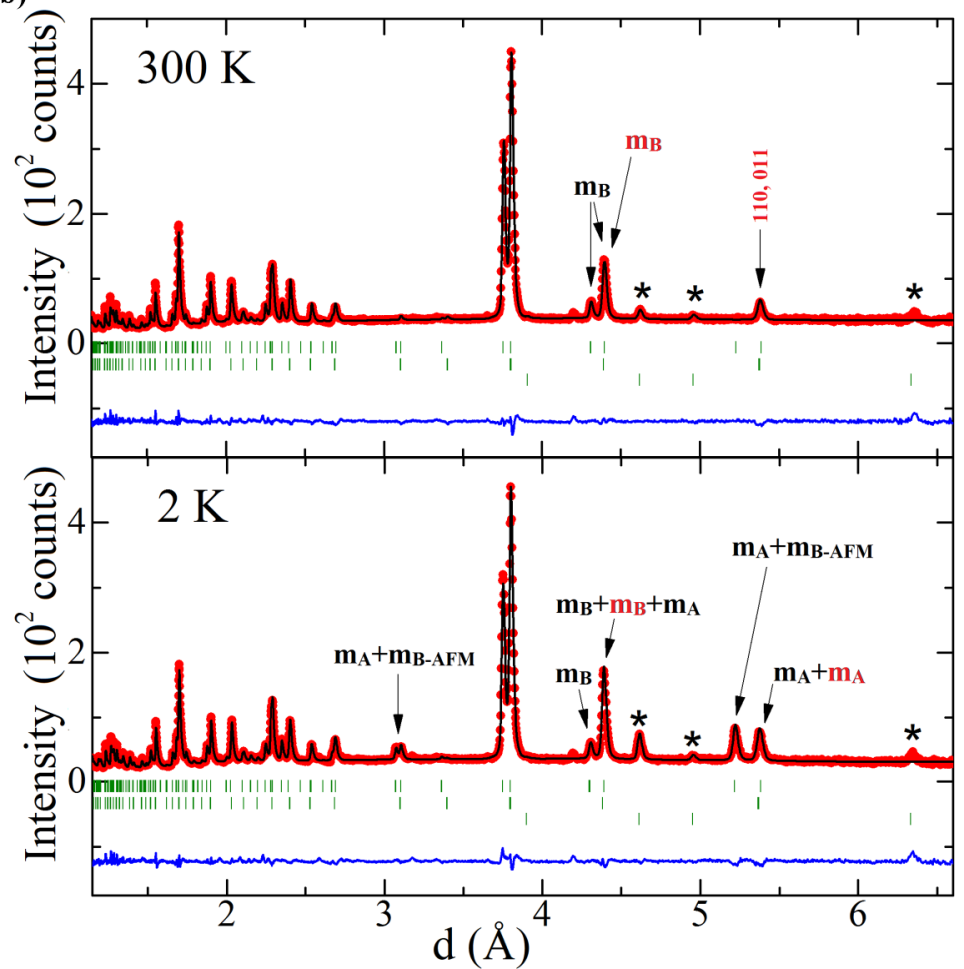

(c)

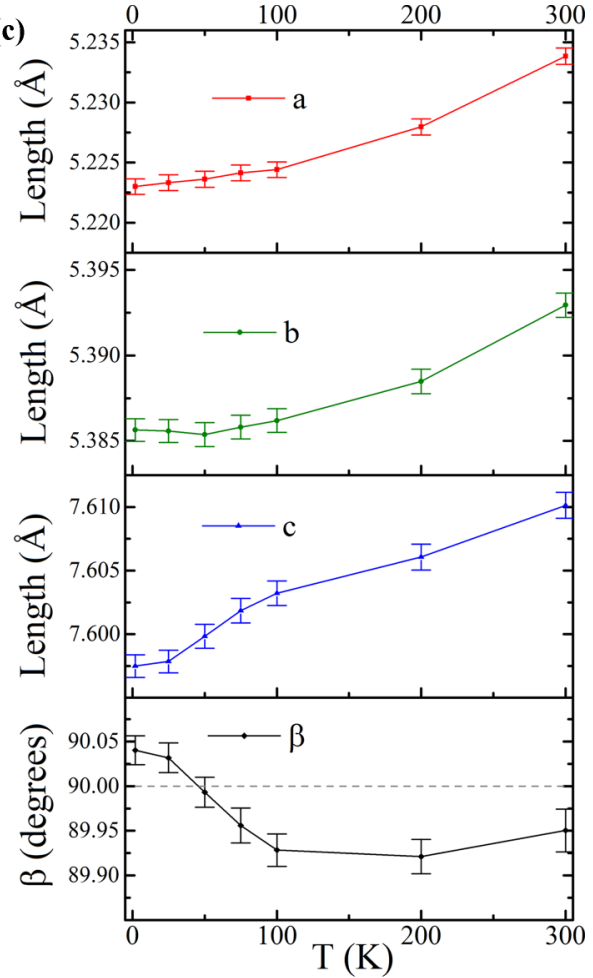

(d)

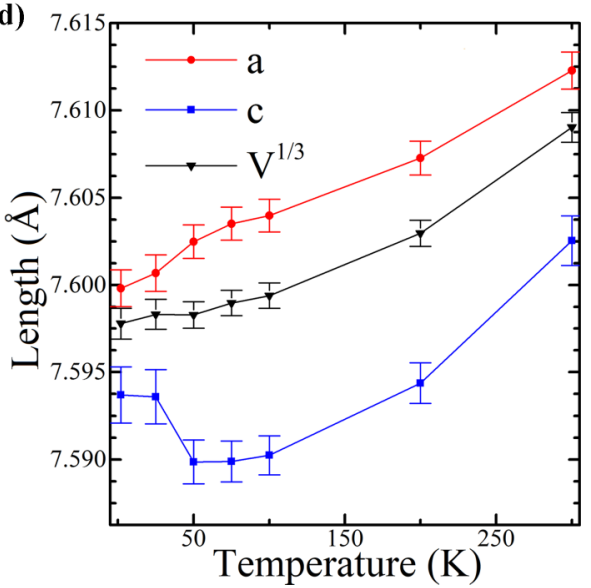

FIG. 4. Results for the nominal $\mathrm{Ca}_{0.5} \mathrm{Mn}_{1.5} \mathrm{FeReO}_{6}(x=0.5)$ sample. Fits to (a) 300-K PSXRD and (b) 2- and 300-K PND profiles. The $x=0.5(T)$ phase is indicated with red labels, while the $x=0.5(M)$ phase is indicated by black labels. Designations $m_{\mathrm{A}} / m_{\mathrm{B}}$ indicate reflections that have magnetic contributions from $A$ - or $B$-site spin order and $m_{\mathrm{B}-\mathrm{AFM}}$ refers to the antiferromagnetic component of $\mathrm{Fe} / \mathrm{Re}$ spin order along the $b$ axis due to frustration. Asterisks mark a small $\mathrm{MnFe}_{3} \mathrm{O}_{5}$ impurity. Thermal variations of PND lattice parameters for $(\mathrm{c}) x=0.5(M)$ and (d) $x=0.5(T)$ phases.

region of the $\mathrm{Ca}_{x} \mathrm{Mn}_{2-x} \mathrm{FeReO}_{6}$ system under the present synthesis conditions. 5.3(2)\% Fe/Re- $B / B^{\prime}$-antisite disorder is found from the PSXRD fit for the $x=1.5(M)$ phase, which is very similar to above values for $x=0.5(M)$ and $x=0.5(T)$ phases, demonstrating that the degree of $B / B^{\prime}$ site ordering is very constant across the series.

The magnetic behavior of the $x=1.5(M)$ phase shows qualitatively similar behavior to that of the $x=2 \mathrm{Ca}_{2} \mathrm{FeReO}_{6}$ material [6,12], and no long-range order of the $A$-site Mn spins is observed by PND, likely because of the low Mn concentration. The high-temperature PND data are fitted by the same ferrimagnetic model as for $\mathrm{Mn}_{2} \mathrm{FeReO}_{6}$, with $\mathrm{Fe} / \mathrm{Re}$ moments in the $a c$ plane, with only a small component along the $a$ axis and the majority of the spin directed along the $c$ axis. The Fe moments are near the octahedral tilt direction, $\theta_{\text {Tilt }} \approx 20^{\circ}$. Below $T_{\text {sr }}=100 \mathrm{~K}$ there is a significant reorientation of Fe/Re spins and these gain significant $y$ components while remaining ferrimagnetically ordered. Anomalies in thermal expansion of $\mathrm{Re}-\mathrm{O}$ bonds near the $100 \mathrm{~K}$ spin reorientation [Fig. 5(d)] are consistent with a $\mathrm{Re}^{5+}$ orbital ordering transition, suppressed from the $140-\mathrm{K}$ value reported for $\mathrm{Ca}_{2} \mathrm{FeReO}_{6}$ [12] by $\mathrm{Mn}$ doping. Electronic phase separation was previously reported in some studies of $\mathrm{Ca}_{2} \mathrm{FeReO}_{6}[13,14]$ and may result from different spin-orbit coupled phases but we do not observe any such separation in the $x=1.5(M)$ double perovskite phase $\left(\mathrm{Ca}_{1.73} \mathrm{Mn}_{0.27}\right) \mathrm{FeReO}_{6}$ here. 
(a)

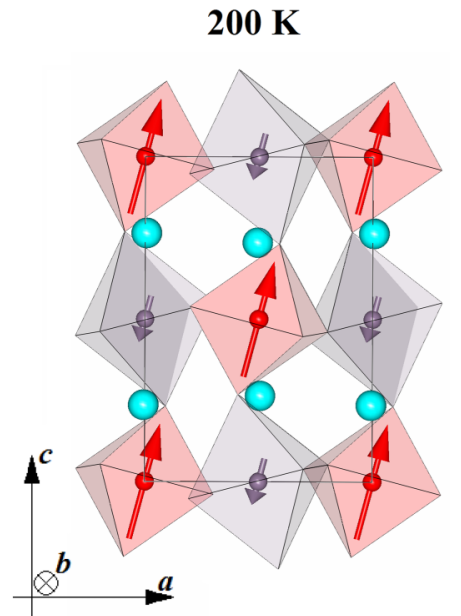

$2 \mathrm{~K}$

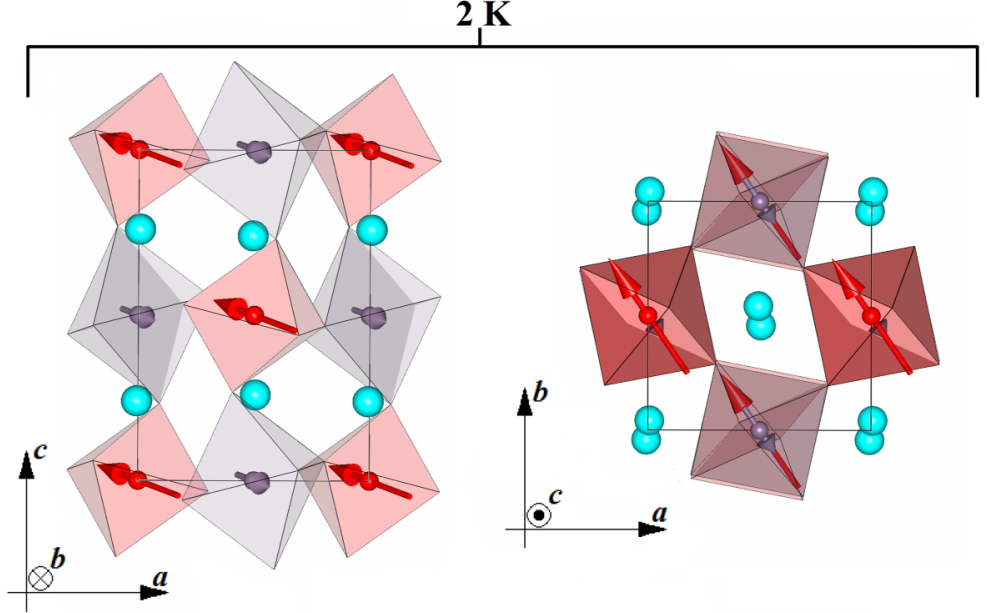

(b)

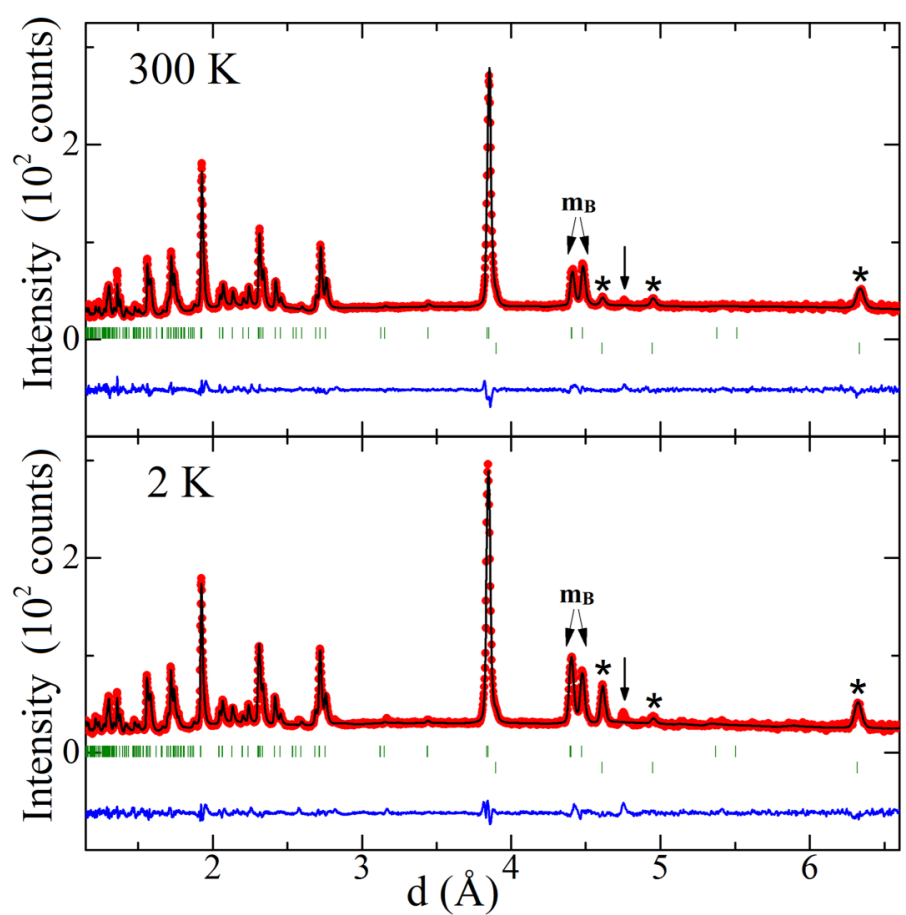

(c)

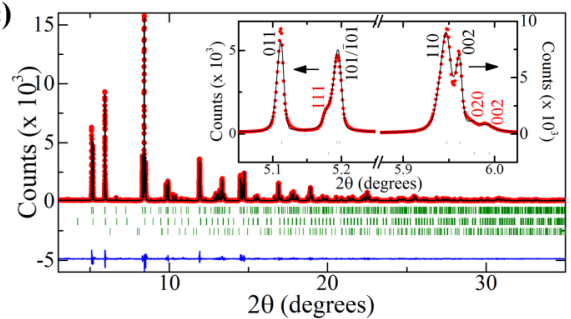

(d)

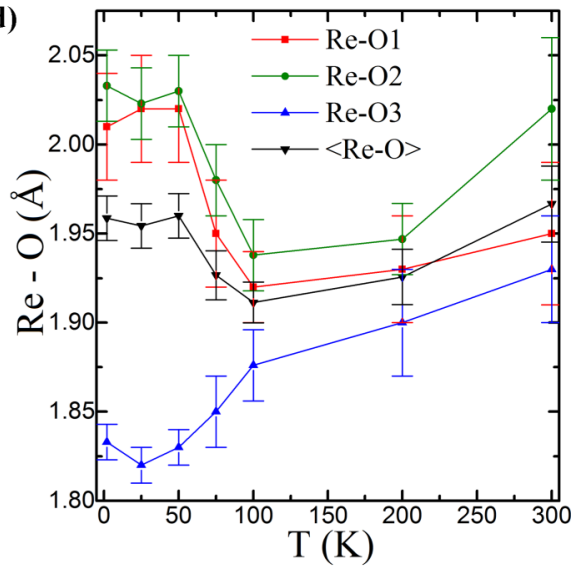

FIG. 5. Results for the nominal $\mathrm{Ca}_{1.5} \mathrm{Mn}_{0.5} \mathrm{FeReO}_{6}(x=1.5)$ sample. (a) Crystal and magnetic structures of the $x=1.5(M)$ phase at 200 and $2 \mathrm{~K}$. Fe atoms are shown in red, Re in grey, and $\mathrm{Ca} / \mathrm{Mn}$ sites in cyan. Magnetic spin structures are shown in the $a c$ plane as well as the $a b$ plane at $2 \mathrm{~K}$ regime to show spin orientation. (b) 2- and 300-K PND patterns showing the fit of the $x=1.5(M)$ phase. Reflections marked as $m_{\mathrm{B}}$ have magnetic contributions from $B$-site magnetic order, no ordered moment from $A$-site Mn is observed from PND. Asterisks mark a small $\mathrm{MnFe}_{3} \mathrm{O}_{5}$ impurity. (c) PSXRD data at $300 \mathrm{~K}$. Rows of markers from top to bottom indicate the $x=1.5(M)$ double perovskite phase [88.0(2)\% by weight, $h k l$ indices in the inset in black], the $x=1.5(T)$ double-double perovskite phase [11.88(6)\% by weight, indices in red], and $\mathrm{ReO}_{2}$ impurity [0.09(1)\% by weight]. (d) Thermal variations of PND Re-O bond distances in the $x=1.5(M)$ structure.

\section{B. X-ray magnetic circular dichroism}

As neutron-diffraction intensities are insensitive to $S=$ $1 \mathrm{Re}^{5+}$ moments in the presence of large ordered $\mathrm{Mn}^{2+}$ and $\mathrm{Fe}^{3+} S=5 / 2$ spins, the Re magnetism has been further investigated using $\mathrm{X}$-ray magnetic circular dichroism (XMCD). X-ray-absorption near-edge spectra (XANES) and the derived XMCD data for $\operatorname{Re} L_{2}$ and $L_{3}$ edges are shown for the $x=0$ sample $\left(\mathrm{Mn}_{2} \mathrm{FeReO}_{6}\right)$ in Fig. 6, and similar spectra for $x=1$ and 1.5 are shown in [31]. Qualitatively, XANES and XMCD spectral shapes bear strong similarities with those in former studies of $A_{2} \mathrm{FeReO}_{6}$ double perovskites with $A=\mathrm{Ca}, \mathrm{Sr}$, or $\mathrm{Ba}[10,33-35]$. Re XANES spectra for all $\mathrm{Ca}_{x} \mathrm{Mn}_{2-x} \mathrm{FeReO}_{6}$ samples have same shapes and edge positions (within $\sim 0.2 \mathrm{eV}$ ) indicating that $\mathrm{Re}$ valence remains essentially constant with $\mathrm{Mn}$ for Ca substitution. A double-peak white-line structure is observed at both $\operatorname{Re} L_{2}$ and $L_{3}$ edges. The white line peak splitting of $\sim 3.0 \mathrm{eV}$ reflects the octahedral crystal-field splitting of the $5 d$ orbitals of $\mathrm{Re}^{5+}$ into $t_{2 \mathrm{~g}}$ and $e_{g}$ states $[10,33,35,36]$. While XMCD at the $\operatorname{Re} L_{3}$ edge shows a differential shape of limited integral, a largely dominant negative XMCD signal 

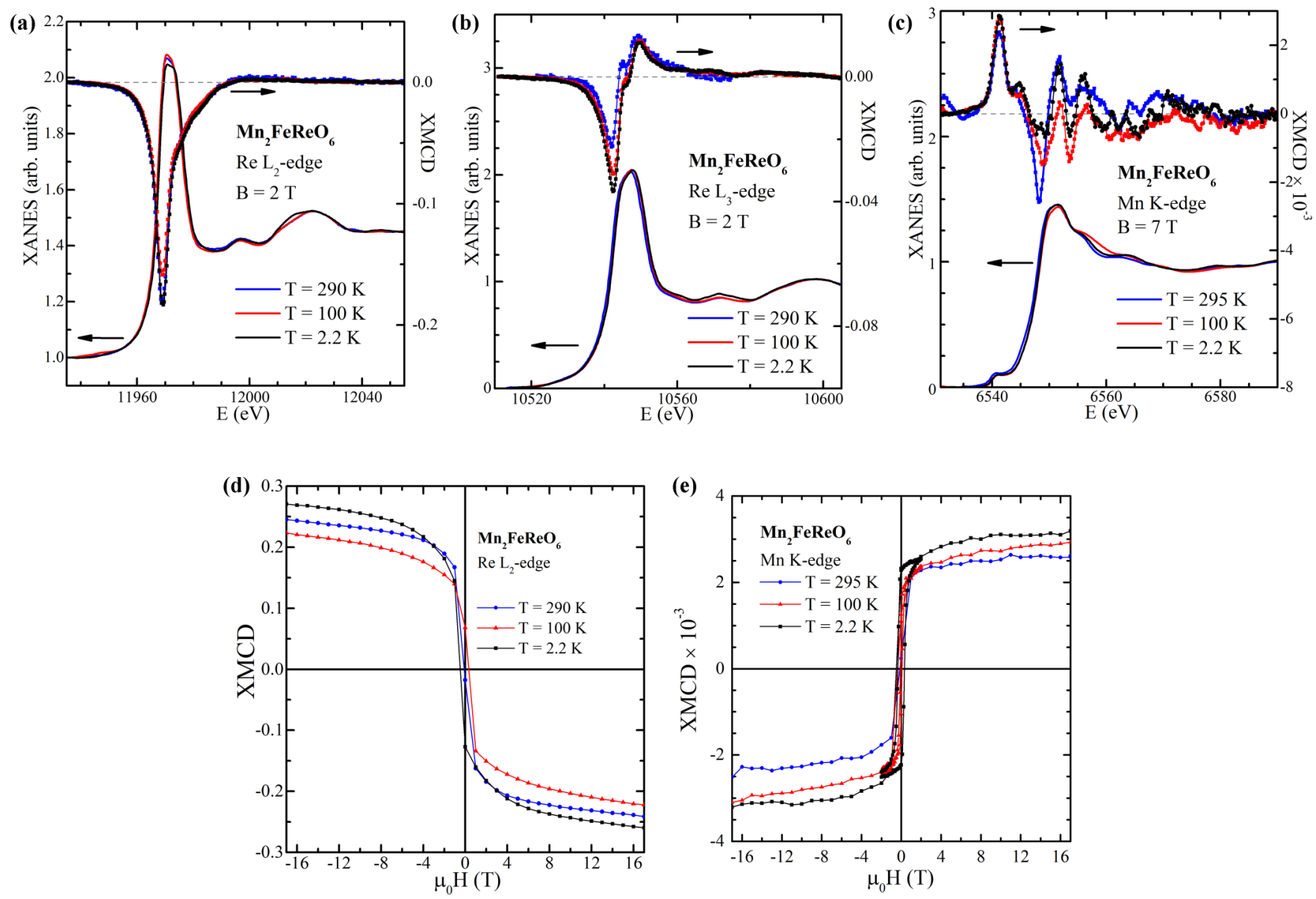

FIG. 6. X-ray-absorption near-edge spectra (XANES) and x-ray magnetic circular dichroism (XMCD) data for $\mathrm{Mn}_{2} \mathrm{Fe} \mathrm{ReO}_{6}$ at $(\mathrm{a}) \mathrm{Re} L_{2}$ edge, (b) Re $L_{3}$ edge, and (c) Mn $K$ edge, at several temperatures. XMCD hysteresis of (d) the Re $L_{2}$-edge and (e) the Mn $K$-edge signals.

is observed at the $L_{2}$ edge which indicates Re spin moments aligned antiparallel to the applied field. More quantitatively, spin $\left(m_{S}\right)$, orbit $\left(m_{L}\right)$, and total $\left(m=m_{S}+m_{L}\right)$ moments for Re moments were derived by applying standard sum rules $[37,38]$ to the integrals of the XANES and XMCD spectra in the vicinity of the absorption edge. The magnetic dipole operator $\left\langle T_{z}\right\rangle$ is neglected as done in previous reports on closely related double perovskites [33-36]. The number of $d$-state electron holes is taken to be $n_{h}=8$ (corresponding to the closest integral charge distribution, $\left.\mathrm{Ca}_{x} \mathrm{Mn}_{2-x} \mathrm{Fe}^{3+} \mathrm{Re}^{5+} \mathrm{O}_{6}\right)$ although values calculated for $n_{h}=9\left(\mathrm{Ca}_{x} \mathrm{Mn}_{2-x} \mathrm{Fe}^{2+} \mathrm{Re}^{6+} \mathrm{O}_{6}\right)$ differ by $<0.1 \mu_{\mathrm{B}}$ Results are summarized in Table II, and the field dependence of the $\mathrm{Re} L_{2} \mathrm{XMCD}$ signal for $\mathrm{Mn}_{2} \mathrm{FeReO}_{6}$ is shown in Fig. 6(d).

The Re XMCD results demonstrate that Re moments in $\mathrm{Ca}_{x} \mathrm{Mn}_{2-x} \mathrm{FeReO}_{6}$ spin ordered structures are negative (antiparallel to the majority $\mathrm{Fe}$ moments), in keeping with the expected ferrimagnetism. A substantial orbital moment is present as expected for orbitally degenerate $5 d^{2} \mathrm{Re}^{5+}$ and does not show any dependence on $x$, but does increase slightly at low temperatures. At $290 \mathrm{~K}$, the orbital-to-spin moment ratio $\left|m_{L} / m_{S}\right|$-which is independent of the estimate of $n_{h}$-amounts to $0.28,0.29$, and 0.33 for $x=0,1$, and 1.5 , respectively. These ratios are close to those reported (0.270.34 ) for $A_{2} \mathrm{FeReO}_{6}$ double perovskites with nonmagnetic atoms on the $A$ site [33-35]. For $\mathrm{Mn}_{2} \mathrm{FeReO}_{6}$, the temperature evolution of the $\left|m_{L} / m_{S}\right|$ ratio appears to be non-negligible (increasing to 0.39 at $2.2 \mathrm{~K}$ ) and the total moments at 2.2 and $100 \mathrm{~K}$ are smaller than those at $290 \mathrm{~K}$ (Table II). This is likely to be a result of canting in the Fe/Re spin structure, as XMCD only reflects a net magnetic moment along the applied magnetic field direction. This provides further evidence for a canting of the $\mathrm{Fe} / \mathrm{Re}$ sublattice due to $\mathrm{Mn}$ spin order and $\mathrm{Re}^{5+}$ orbital order. We also note that while the XMCD field dependence for Re shows a rapid moment alignment at low field (below $0.5 \mathrm{~T}$ ), it is not fully saturated even in a 17-T field, so that the intrinsic moment of Re may be underestimated.

TABLE II. Calculated spin $\left(m_{S}\right)$, orbit $\left(m_{L}\right)$, and total $\left(m=m_{L}+\right.$ $m_{S}$ ) moments for Re derived from XMCD data for $\mathrm{Ca}_{x} \mathrm{Mn}_{2-x} \mathrm{FeReO}_{6}$ samples recorded in a 2 -T magnetic field at several temperatures and considering a magnetic dipole operator $\left\langle T_{z}\right\rangle=0$.

\begin{tabular}{lcccc}
\hline \hline$x$ & $T(\mathrm{~K})$ & $m_{S}\left(\mu_{\mathrm{B}}\right)$ & $m_{L}\left(\mu_{\mathrm{B}}\right)$ & $m\left(\mu_{\mathrm{B}}\right)$ \\
\hline 0 & 290 & -0.74 & 0.21 & -0.53 \\
0 & 100 & -0.64 & 0.24 & -0.40 \\
0 & 2.2 & -0.72 & 0.28 & -0.44 \\
1.0 & 290 & -0.48 & 0.14 & -0.34 \\
1.0 & 2.2 & -0.72 & 0.21 & -0.51 \\
1.5 & 290 & -0.66 & 0.22 & -0.45 \\
\hline \hline
\end{tabular}


Fields in excess of $30 \mathrm{~T}$ are reported to be needed to fully saturate $\mathrm{Ca}_{2} \mathrm{FeReO}_{6}[6,39]$.

Mn $K$-edge XMCD data were also collected for $\mathrm{Mn}_{2} \mathrm{FeReO}_{6}$ [Fig. 6(c)]. The field dependence of the XMCD signal [Fig. 6(e)] shows a rapid alignment of the Mn moments and reveals a small magnetic hysteresis. The shape and magnitude of the high-field Mn XMCD spectra do not differ greatly between $295 \mathrm{~K}$ (where Mn spins are paramagnetic), $100 \mathrm{~K}$ (induced Mn order), and $2.2 \mathrm{~K}$ (Mn spins reoriented). This suggests that the orbital moment on the Mn $4 p$ states is strongly influenced by neighboring $\mathrm{Fe} / \mathrm{Re}$ atoms and only is weakly affected by the development of the antiferromagnetic order of $\mathrm{Mn}$ at low temperature.

\section{Magnetization}

Magnetization plots in Fig. 7(a) show that all of the $\mathrm{Ca}_{x} \mathrm{Mn}_{2-x} \mathrm{FeReO}_{6}$ samples display ferrimagnetism with high ordering temperatures of $T_{\mathrm{C}}=500$ to $550 \mathrm{~K}$. However, it is not possible to distinguish $T_{\mathrm{C}}$ values for the double and double-double perovskite phases within the two-phase $x=$ 0.5 and $x=1.5$ samples, and their Curie transitions are not broader than those of the single phase $x=0$ and 1.0 samples. Hence it is likely that the double and double-double perovskite phases have very close $T_{\mathrm{C}}$ 's showing that the strength of the Fe-Re magnetic exchange varies little with structure type or composition in this system. Features due to $A$-site $\mathrm{Mn}$ ordering and $\mathrm{Re}^{5+}$ orbital ordering transitions are also evident. In the Mn-rich double perovskites, the spin reorientation transition is evident by a maximum at $75 \mathrm{~K}$ for $x=0$, and an inflection at $100 \mathrm{~K}$ for the $x=0.5(M)$ phase. Mn-spin order in the $x=0.5(T)$ and $x=1$ double-double perovskites gives rise to a low-temperature upturn in magnetization. This corresponds to the second ferrimagnetic transition of Mn spins in the two different $A$-column sites, as evidenced by the data in Fig. 7(b).

Low- $x \mathrm{Ca}_{x} \mathrm{Mn}_{2-x} \mathrm{FeReO}_{6}$ samples have small magnetic coercivities of $<0.1 \mathrm{~T}$ at low temperatures. However, the coercive field increases to $0.5 \mathrm{~T}$ for the $x=1.5(M)$ sample, in keeping with the $0.95 \mathrm{~T}$ value reported for $x=2$ [12]. Although the $\mathrm{Re}^{5+}$ orbital ordering transition is observed across the range of double perovskite phases, it appears that the replacement of nonmagnetic $\mathrm{Ca}$ by magnetic Mn lowers the anisotropy of the system.

\section{DISCUSSION AND CONCLUSIONS}

A phase diagram for the $\mathrm{Ca}_{x} \mathrm{Mn}_{2-x} \mathrm{FeReO}_{6}$ system and variations of magnetic and lattice parameters with $x$ derived from the above results are shown in Fig. 8. These show the determined compositions for the $x=0.5(M)$ and $x=0.5(T)$ and the $x=1.5(M)$ and $x=1.5(T)$ materials in the phaseseparated samples. Although $\mathrm{Ca}_{2} \mathrm{FeReO}_{6}$ and $\mathrm{Mn}_{2} \mathrm{FeReO}_{6}$ are both monoclinic $P 2_{1} / n$ double perovskites with quite similar lattice parameters, their $\mathrm{Ca}_{x} \mathrm{Mn}_{2-x} \mathrm{FeReO}_{6}$ solid solution range is limited to the $0<x<0.17$ and $1.73<x<2$ end regions. This demonstrates similar small levels of substitution in the two members under the $10 \mathrm{GPa}$ and $1673 \mathrm{~K}$ synthesis conditions used here, i.e., up to $8.5 \% \mathrm{Ca}$ substitutes in $\mathrm{Mn}_{2} \mathrm{FeReO}_{6}$ and up to $13.5 \% \mathrm{Mn}$ in $\mathrm{Ca}_{2} \mathrm{FeReO}_{6}$. The
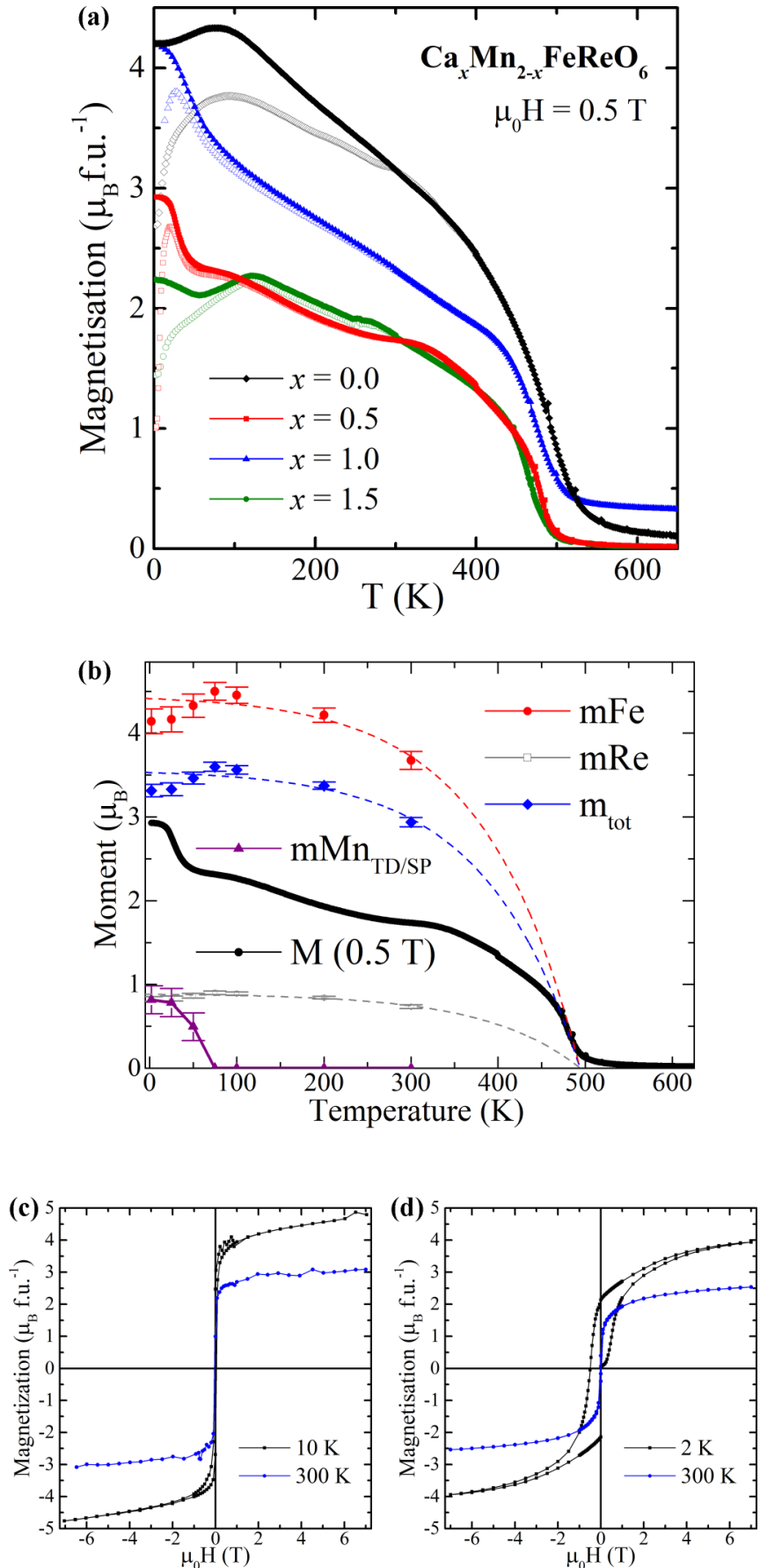

FIG. 7. Magnetization measurements for $\mathrm{Ca}_{x} \mathrm{Mn}_{2-x} \mathrm{FeReO}_{6}$ samples. (a) Field-cooled (filled symbols) and zero-field-cooled (open symbols) for all samples in a 0.5-T field. (b) Field-cooled magnetization for the $x=0.5$ sample, compared against moments at the $\mathrm{Mn}, \mathrm{Fe}$, and Re sites and the net moment $m=m_{\mathrm{Fe}}-m_{\mathrm{Re}}$ from neutron refinements of the $x=0.5(T)$ double-double perovskite phase. Magnetic hysteresis data for (c) the $x=0.5$ and (d) the $x=1.5$ samples.

central region of the phase diagram is occupied by the tetragonal $\mathrm{P}_{2} / n$ double-double perovskite of ideal composition $\mathrm{CaMnFeReO}_{6}$ where $\mathrm{Ca}$ and $\mathrm{Mn}$ cations are ordered into distinct $A$-site columns. This phase is found to have composition range $0.74<x<\sim 1.1$, showing that up to $26 \%$ Mn can be 


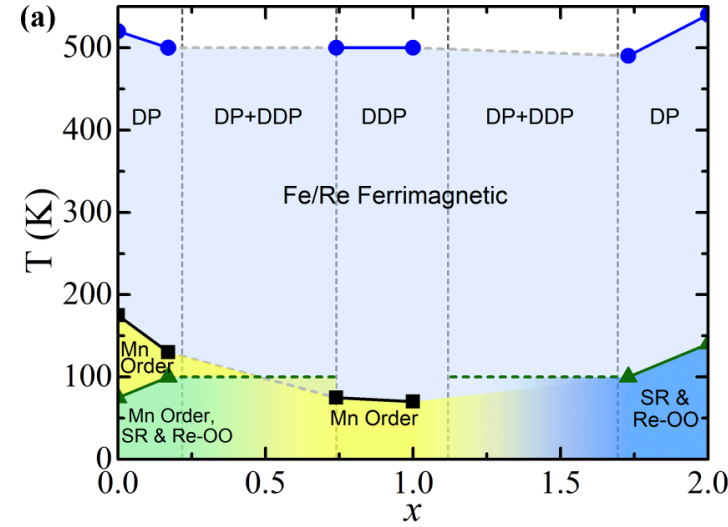

(b)
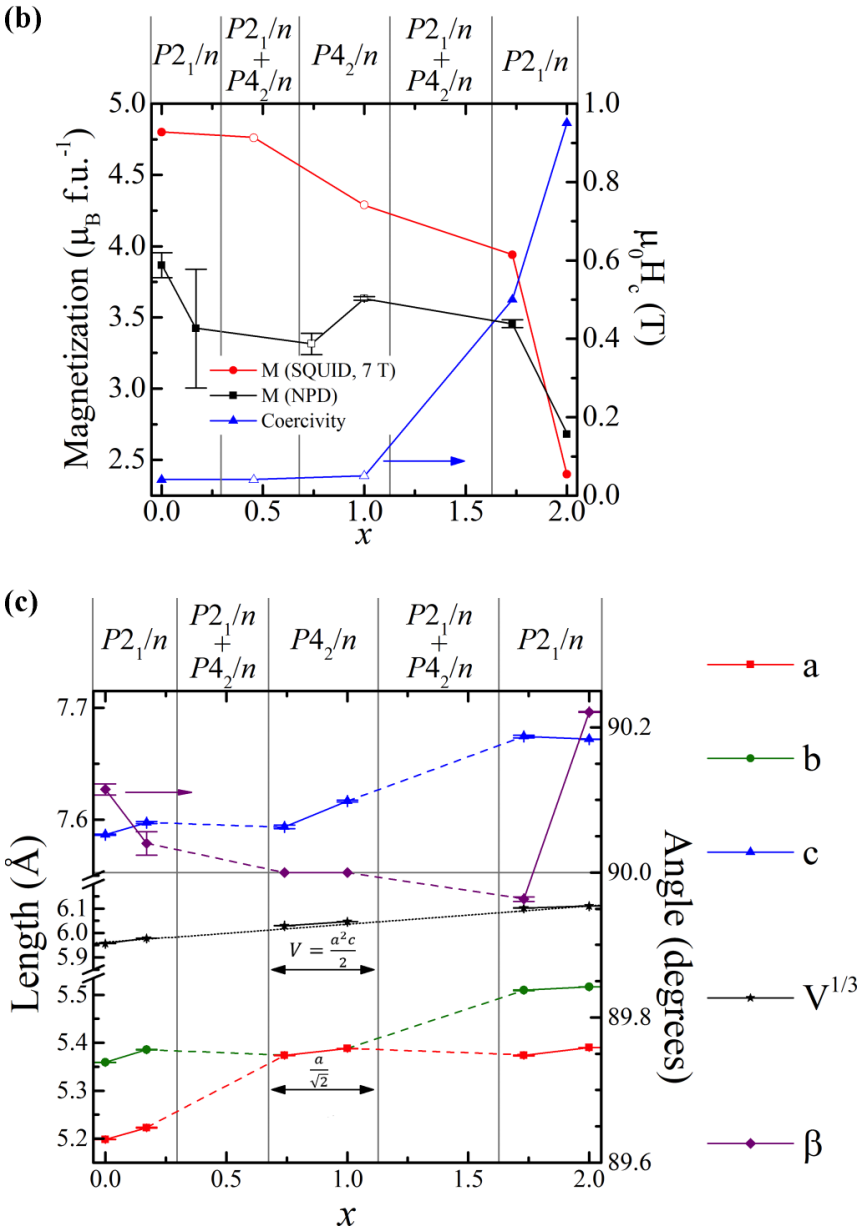

FIG. 8. Overall trends in the $\mathrm{Ca}_{x} \mathrm{Mn}_{2-x} \mathrm{FeReO}_{6}$ system. (a) Phase diagram showing ferrimagnetic $B$-site order, $T_{\mathrm{C}}$, low temperature $A$-site Mn spin ordering, $T_{\mathrm{Mn}}$, and spin reorientation and Re orbital ordering, $T_{\text {sr }}$, transitions. (b) Evolution of the maximum magnetization, as measured by superconducting quantum interference device magnetometry in a 7-T field and from moments refined by neutron diffraction, and the low-temperature coercive field. (c) Evolution of lattice parameters. Panels (b) and (c) show the estimated single-phase double perovskite $\left(P 2_{1} / n\right)$ and double-double perovskite $\left(P 4_{2} / n\right)$ regions, and the regions of phase coexistence $\left(P 2_{1} / n+P 4_{2} / n\right)$.

substituted at the ten-coordinate $\mathrm{Ca}$ sites in the double-double perovskite structure, but only a small amount, $\sim 10 \%$, of $\mathrm{Ca}$ can replace $\mathrm{Mn}$. This likely reflects the small size of the four-coordinated $\mathrm{Mn}^{2+} A$ sites. The limited substitutions of
$\mathrm{Ca}$ and $\mathrm{Mn}$ for each other in both the double and doubledouble perovskite structures result in substantial co-existence regions. Analysis of the nominal $x=0.5$ and 1.5 samples reveals that the two-phase regions cover $0.17<x<0.74$ and $\sim 1.1<x<1.73$ compositions. No other phases are found in the $\mathrm{Ca}_{x} \mathrm{Mn}_{2-x} \mathrm{FeReO}_{6}$ system.

The large coexistence regions of double and double-double perovskite structures appear surprising in view of previous work on the $R \mathrm{MnMnSbO}_{6}(R=$ rare earth) series, the only other system reported so far in which both structure types appear [26]. $R=\mathrm{La}, \mathrm{Pr}, \mathrm{Nd}, \mathrm{Sm}$ materials formed tetragonal $P 4_{2} / n R \mathrm{MnMnSbO}_{6}$ double-double perovskites with full $A / A^{\prime}$ ordering of $R^{3+}$ and $\mathrm{Mn}^{2+}$ cations, whereas monoclinic $P 2_{1} / n$ $\left(R_{0.5} \mathrm{Mn}_{0.5}\right)_{2} \mathrm{FeReO}_{6}$ double perovskites with no long-range $R^{3+} / \mathrm{Mn}^{2+}$ order were found for $R=\mathrm{Eu}$ and $\mathrm{Gd}$. No secondary phase of a double perovskite was observed for $R=\mathrm{Sm}$ and no double-double impurity was seen for $R=$ Eu despite the very similar ionic radii of their $R^{3+}$ cations, demonstrating that the structural boundary is sharp with no apparent coexistence region. The key distinction may be the charge difference between $R^{3+}$ and $\mathrm{Mn}^{2+}$ cations which disfavors separation into two $R_{y} \mathrm{Mn}_{2-y} \mathrm{MnSbO}_{6}$ phases with $y \neq 1$ as there is no facile charge compensation mechanism, whereas segregation of $\mathrm{Ca}^{2+}$ and $\mathrm{Mn}^{2+}$ in the $\mathrm{Ca}_{x} \mathrm{Mn}_{2-x} \mathrm{FeReO}_{6}$ system can occur without need for charge compensation. There are clearly many opportunities to explore double-double double perovskite relationships in other $\left(A, A^{\prime}\right)_{2} B B^{\prime} \mathrm{O}_{6}$ systems using high pressure.

All $\mathrm{Ca}_{x} \mathrm{Mn}_{2-x} \mathrm{FeReO}_{6}$ compositions are found to be ferrimagnetic with Curie temperatures near $500 \mathrm{~K}$. This demonstrates that the $B$-site $\mathrm{Fe} / \mathrm{Re}$ spin order is robust with exchange interactions that are relatively insensitive to the structure type and cation ordering between double and double-double perovskite types. XMCD confirms that Re moments are antiparallel to the bulk magnetization direction determined by the $\mathrm{Fe}$ and $\mathrm{Mn}$ spins, and show large orbital moments consistent with the orbital ordering at low temperatures. It was not possible to distinguish separate $T_{\mathrm{C}}$ 's for the double and double-double perovskite phases within the mixed phase $x=0.5$ and 1.5 samples. The highest values of $T_{\mathrm{C}}=520$ and $540 \mathrm{~K}$ are found for $\mathrm{Mn}_{2} \mathrm{FeReO}_{6}$ and $\mathrm{Ca}_{2} \mathrm{FeReO}_{6}$ respectively, with disorder due to substitution by $\mathrm{Ca}$ or Mn lowering the transition temperature. Low-temperature $\mathrm{Mn}$ spin order is observed in the Mn-rich double perovskites and the double-double perovskite phases, with the maximum ordering temperature of $175 \mathrm{~K}$ at the highest Mn content $(x=0)$. However, Mn spins within the Ca-rich $1.73 \leqslant x<2$ double perovskite region remain paramagnetic to the lowest measured temperatures. Spin reorientation transitions accompanying orbital ordering of $5 d^{2}$ $\mathrm{Re}^{5+}$ are observed across all of the double perovskites, with $T_{\text {sr }}$ falling from $140 \mathrm{~K}$ in $\mathrm{Ca}_{2} \mathrm{FeReO}_{6}$ to $75 \mathrm{~K}_{\text {in }} \mathrm{Mn}_{2} \mathrm{FeReO}_{6}$. However, no spin reorientation or Jahn-Teller distortion of $\mathrm{ReO}_{6}$ octahedra is evident for the double-double perovskite phases, and this may be suppressed by the rigidity of the $B / B^{\prime} \mathrm{O}_{6}$ network and large octahedral tilt angles within this structural type.

The maximum low-temperature magnetization, measured at $7 \mathrm{~T}$, decreases slightly with rising $x$, from $4.6 \mu_{\mathrm{B}}$ at $x=0$ to $4.0 \mu_{\mathrm{B}}$ at $x=1.5$, and then falls to $2.4 \mu_{\mathrm{B}}$ in $\mathrm{Ca}_{2} \mathrm{FeReO}_{6}$ [Fig. 7(b)]. Estimated values from the ordered moments 
observed by neutron scattering are lower for $x=0$ to 1.5 samples, but similar to the maximum magnetization at $x=2$. These observations demonstrate that the paramagnetic (in Mn-rich double perovskites) or ferrimagnetic (in the doubledouble phases) $A$-site Mn spins supplement the magnetization due to the ferrimagnetic order of $B$-site $\mathrm{Fe}^{3+}$ and $\mathrm{Re}^{5+}$ moments. Mn-rich materials are soft magnets with coercive fields $<0.1 \mathrm{~T}$ at low temperatures, but the Ca-rich double perovskites have significant magnetic anisotropy with a coercive field of $0.95 \mathrm{~T}$ reported for $\mathrm{Ca}_{2} \mathrm{FeReO}_{6}$. The variations in coercivity do not reflect changes in structural anisotropy, as the monoclinic lattice distortion and low-temperature orbital order are fairly constant across all the double perovskite compositions, and so probably reflect the presence of $A$-site Mn spins that lower the energy barrier to $\mathrm{Fe} / \mathrm{Re}$ spin reversal at low $x$.

In summary, only a limited range of $\mathrm{Ca}_{x} \mathrm{Mn}_{2-x} \mathrm{FeReO}_{6}$ solid solutions close to the end members $(0<x<0.17$ and $1.73<x<2$ ) are formed between $\mathrm{Mn}_{2} \mathrm{FeReO}_{6}$ and $\mathrm{Ca}_{2} \mathrm{FeReO}_{6}$, despite both having monoclinic $P 2_{1} / n$ double perovskite structures with similar lattice parameters. Additional 1:1 $A$-site ordering stabilizes a double-double perovskite phase based on the structure of $\mathrm{CaMnFeReO}_{6}$ for $0.74<x<\sim 1.1$. Wide regions of double-double-double perovskite phase coexistence occur between these limits. This is likely due to the facile segregation of $\mathrm{Ca}^{2+}$ and $\mathrm{Mn}^{2+}$ cations between the two structure types, unlike in the previ- ously reported $R \mathrm{MnMnSbO}_{6}$ system where no phase separation was observed. All $\mathrm{Ca}_{x} \mathrm{Mn}_{2-x} \mathrm{FeReO}_{6}$ compositions are found to be ferrimagnetic with Curie temperatures for $\mathrm{Fe} / \mathrm{Re}$ spin order near $500 \mathrm{~K}$. Mn spin order is observed below $175 \mathrm{~K}$ in the Mn-rich double perovskites and the double-double perovskite phases, but Mn spins within Ca-rich $1.73 \leqslant x<2$ double perovskites remain paramagnetic to below $2 \mathrm{~K}$. A spin reorientation transition accompanying orbital ordering of $5 d^{2}$ $\mathrm{Re}^{5+}$ is observed across the double perovskites, decreasing from $140 \mathrm{~K}$ at $x=2$ to $75 \mathrm{~K}$ at $x=0$. XMCD confirms that $\mathrm{Re}$ moments are antiparallel to Fe and Mn spins, and show large orbital moments consistent with the orbital ordering. However, no orbital ordering transition is observed in the double-double perovskite phases, likely due to the rigidity and large octahedral tilt angles of this structural type. High pressures are required to access these materials, and future investigation of other transition metal $\left(A, A^{\prime}\right)_{2} B B^{\prime} \mathrm{O}_{6}$ systems may lead to discoveries of other interesting electronic and magnetic materials.

\section{ACKNOWLEDGMENTS}

We thank UK Engineering and Physical Sciences Research Council (EPSRC) for support and STFC for provision of beam time at ISIS and ESRF.
[1] G. King and P. M. Woodward, J. Mater. Chem. 20, 5785 (2010).

[2] S. Vasala and M. Karppinen, Prog. Solid State Chem. 43, 1 (2015).

[3] K. Kobayashi, T. Kimura, H. Sawada, K. Terakura, and Y. Tokura, Nature (London) 395, 677 (1998).

[4] O. Chmaissem, R. Kruk, B. Dabrowski, D. E. Brown, X. Xiong, S. Kolesnik, J. D. Jorgensen, and C. W. Kimball, Phys. Rev. B 62, 14197 (2000).

[5] D. Serrate, J. M. De Teresa, and M. R. Ibarra, J. Phys.: Condens. Matter 19, 023201 (2007).

[6] J. M. De Teresa, D. Serrate, J. Blasco, M. R. Ibarra, and L. Morellon, Phys. Rev. B 69, 144401 (2004).

[7] C. Azimonte and E. Granado, J. Appl. Phys. 101, 09H115 (2007).

[8] M. Sikora, O. Mathon, P. van der Linden, J. M. Michalik, J. M. de Teresa, Cz. Kapusta, and S. Pascarelli, Phys. Rev. B 79, 220402(R) (2009).

[9] V. N. Antonov, L. V. Bekenov, and A. Ernst, Phys. Rev. B 94, 035122 (2016).

[10] C. A. Escanhoela Jr., G. Fabbris, F. Sun, C. Park, J. Gopalakrishnan, K. Ramesha, E. Granado, N. M. Souza-Neto, M. van Veenendaal, and D. Haskel, Phys. Rev. B 98, 054402 (2018).

[11] E. Granado, J. C. Cezar, C. Azimonte, J. Gopalakrishnan, and K. Ramesha, Phys. Rev. B 99, 195118 (2019).

[12] K. Oikawa, T. Kamiyama, H. Kato, and Y. Tokura, J. Phys. Soc. Jpn. 72, 1411 (2003).

[13] E. Granado, Q. Huang, J. W. Lynn, J. Gopalakrishnan, R. L. Greene, and K. Ramesha, Phys. Rev. B 66, 064409 (2002).
[14] W. Westerburg, O. Lang, C. Ritter, C. Felser, W. Tremel, and G. Jakob, Solid State Commun. 122, 201 (2002).

[15] E. Solana-Madruga, A. J. Dos santos-García, A. M. ArévaloLópez, D. Ávila-Brande, C. Ritter, J. P. Attfield, and R. SáezPuche, Dalton Trans. 44, 20441 (2015).

[16] A. J. Dos santos-García, E. Solana-Madruga, C. Ritter, D. Ávila-Brande, O. Fabelo, and R. Sáez-Puche, Dalton Trans. 44, 10665 (2015).

[17] A. J. Dos santos-García, C. Ritter, E. Solana-Madruga, and R. Sáez-Puche, J. Phys.: Condens. Matter 25, 206004 (2013).

[18] A. M. Arévalo-López, F. Stegemann, and J. P. Attfield, Chem. Commun. 52, 5558 (2016).

[19] M. R. Li, J. P. Hodges, M. Retuerto, Z. Deng, P. W. Stephens, M. C. Croft, X. Deng, G. Kotliar, J. Sánchez-Benítez, D. Walker, and M. Greenblatt, Chem. Mater. 28, 3148 (2016).

[20] M. R. Li, M. Retuerto, Z. Deng, P. W. Stephens, M. Croft, Q. Huang, H. Wu, X. Deng, G. Kotliar, J. Sánchez-Benítez, J. Hadermann, D. Walker, and M. Greenblatt, Angew. Chem., Int. Ed. 54, 12069 (2015).

[21] A. M. Arévalo-López, G. M. McNally, and J. P. Attfield, Angew. Chem., Int. Ed. 54, 12074 (2015).

[22] C. E. Frank, E. E. McCabe, F. Orlandi, P. Manuel, X. Tan, Z. Deng, M. Croft, V. Cascos, T. Emge, H. L. Feng, S. Lapidus, C. Jin, M. X. Wu, M. R. Li, S. Ehrlich, S. Khalid, N. Quackenbush, S. Yu, D. Walkerk, and M. Greenblatt, Chem. Commun. 55, 3331 (2019).

[23] M.-R. Li, P. W. Stephens, M. Croft, Z. Deng, W. Li, C. Jin, M. Retuerto, J. P. Hodges, C. E. Frank, M. Wu, D. Walker, and M. Greenblatt, Chem. Mater. 30, 4508 (2018). 
[24] A. M. Arévalo-López, E. Solana-Madruga, C. AguilarMaldonado, C. Ritter, O. Mentré, and J. P. Attfield, Chem. Commun. 55, 14470 (2019).

[25] G. M. McNally, Á. M. Arévalo-López, P. Kearins, F. Orlandi, P. Manuel, and J. P. Attfield, Chem. Mater. 29, 8870 (2017).

[26] E. Solana-Madruga, Á. M. Arévalo-López, A. J. Dos SantosGarcía, E. Urones-Garrote, D. Ávila-Brande, R. Sáez-Puche, and J. P. Attfield, Angew. Chem., Int. Ed. 55, 9340 (2016).

[27] E. Solana-Madruga, Á. M. Arévalo-López, A. J. Dos SantosGarcía, C. Ritter, C. Cascales, R. Sáez-Puche, and J. P. Attfield, Phys. Rev. B 97, 134408 (2018).

[28] E. Solana-Madruga, Y. Sun, Á. M. Arévalo-López, and J. P. Attfield, Chem. Commun. 55, 2605 (2019).

[29] L. C. Chapon, P. Manuel, P. G. Radaelli, C. Benson, L. Perrott, S. Ansell, N. J. Rhodes, D. Raspino, D. Duxbury, E. Spill, and J. Norris, Neutron News 22, 22 (2011).

[30] J. Rodriguez-Carvajal, Physica B 192, 55 (1993).

[31] See Supplemental Material at http://link.aps.org/supplemental/ 10.1103/PhysRevMaterials.4.064408 for tables of results from PND and PSXRD refinements and figures showing further PND, XANES, and XMCD data and results plots.
[32] W.-T. Chen, M. Mizumaki, H. Seki, M. S. Senn, T. Saito, D. Kan, J. P. Attfield, and Y. Shimakawa, Nat. Commun. 5, 3909 (2014).

[33] M. Sikora, Cz. Kapusta, M. Borowiec, C. J Oates, V. Prochazka, D. Rybicki, D. Zajac, J. M De Teresa, C. Marquina, and M. R Ibarra, Appl. Phys. Lett. 89, 062509 (2006).

[34] C. Azimonte, J. C. Cezar, E. Granado, Q. Huang, J.W. Lynn, J. C. P. Campoy, J. Gopalakrishnan, and K. Ramesha, Phys. Rev. Lett. 98, 017204 (2007).

[35] A. Winkler, N. Narayanan, D. Mikhailova, K. G. Bramnik, H. Ehrenberg, H. Fuess, G. Vaitheeswaran, V. Kanchana, F. Wilhelm, A. Rogalev, A. Kolchinskaya, and L. Alff, New J. Phys. 11, 073047 (2009).

[36] P. Majewski, S. Geprägs, O. Sanganas, M. Opel, and R. Gross, F. Wilhelm, A. Rogalev, and L. Alff, Appl. Phys. Lett. 87, 202503 (2005).

[37] B. T. Thole, P. Carra, F. Sette, and G. van der Laan, Phys. Rev. Lett. 68, 1943 (1992).

[38] P. Carra, B. T. Thole, M. Altarelli, and X. Wang, Phys. Rev. Lett. 70, 694 (1993).

[39] J. M. De Teresa, J. M. Michalik, J. Blasco, P. A. Algarabel, and M. R. Ibarra, Appl. Phys. Lett. 90, 252514 (2007). 